\title{
Speckle interferometry and orbits of "fast" visual binaries
}

\author{
Andrei Tokovinin \\ Cerro Tololo Inter-American Observatory, Casilla 603, La Serena, Chile \\ atokovinin@ctio.noao.edu
}

\begin{abstract}
Results of speckle observations at the 4.1-m SOAR telescope in 2012 (158 measures of 121 systems, 27 non-resolutions) are reported. The aim is to follow fast orbital motion of recently discovered or neglected close binaries and sub-systems. Here 8 previously known orbits are defined better, two more are completely revised, and five orbits are computed for the first time. Using differential photometry from Hipparcos or speckle and the standard relation between mass and absolute magnitude, the component's masses and dynamical parallaxes are estimated for all 15 systems with new or updated orbits. Two astrometric binaries HIP 54214 and 56245 are resolved here for the first time, another 8 are measured. We highlight several unresolved pairs that may actually be single despite multiple historic measures, such as 104 Tau and f Pup AB. Continued monitoring is needed to understand those enigmatic cases.
\end{abstract}

Subject headings: stars: binaries

\section{Introduction}

Close binaries with fast orbital motion resolved by speckle interferometry and adaptive optics require frequent measures to compute their orbits. This shifts the main problem of visual orbits from insufficiently long time coverage, as typical for binaries studied in the past two centuries, to sparse time sampling. Many close pairs discovered by W. S. Finsen in the 1960s have completed several revolutions, but their orbits still remain undetermined for the lack of data. This is also true for speckle and Hipparcos binaries discovered in the 1980s and 1990s but not followed further. We try to address this issue here by re-visiting close pairs resolved recently and other binaries in need of follow-up.

Knowledge of binary-star orbits is of fundamental value to many areas of astronomy. They provide direct measurements of stellar masses and distances, inform us on the processes of star formation through statistics of orbital elements, and allow dynamical studies of multiple stellar systems, circumstellar matter (Kennedy et al. 2012), and planets (Roberts et al. 2011). A large fraction of visual binaries are late-type stars within $100 \mathrm{pc}$ amenable to search of exo-planets. The current orbit catalog contains some poor or wrong orbital solutions based on insufficient data. The only way to improve the situation is by getting new measures and revising those orbits.

Data on binary-star measures and orbits are collected by the Washington Double Star Catalog, WDS (Mason et al. 2001) 1 and associated archives such as the 4-th Catalog of Interferometric Measurements of Binary Stars, INT42 2 , and the $6^{\text {th }}$ Orbit Catalog of Orbits of Visual Binary Stars, VB6 (Hartkopf, Mason, \& Worley 2001) 3 These resources are extensively used here.

This paper continues series of speckle interferometry observations published by Tokovinin. Mason \& Hartkopf (2010, hereafter TMH10), Tokovinin et al. (2010, hereafter SAM09), and Hartkopf, Tokovinin, \& Mason (2012, HTM12). We used same equipment and data reduction methods.

Section 2 recalls the observing technique and presents new measures and non-resolutions. Up-

${ }^{1}$ See current version at http://ad.usno.navy.mil/wds/

${ }^{2}$ http://ad.usno.navy.mil/wds/int4.html

3 http://ad.usno.navy.mil/wds/orb6.html 
dated and new orbits for 15 systems are given in Section 3 with estimates of masses and dynamical parallaxes and brief comments on each system. In Section 4 we draw attention to two particular groups: resolved pairs with astrometric accelerations and unresolved binaries which are either false discoveries or enigmatic. Section[5]summarizes the results.

\section{New speckle measures}

\subsection{Instrument and observing method}

The observations reported here were obtained with the high-resolution camera (HRCam) - a fast imager designed to work at the 4.1-m SOAR telescope, either with the SOAR Adaptive Module (SAM, Tokovinin et al. 2008) or as a standalone instrument. The HRCam is described by Tokovinin \& Cantarutti (2008). The first series of measurements in THM10 used HRCam installed at the infrared port of SOAR. In 2009 the HRCam worked at SAM during its first-light tests and produced some binary-star measures published in SAM09. It was further used in this mode in HTM12 and here.

The HRCam receives light through the SAM instrument, including its deformable mirror. However, the AO system was not compensating turbulence during these observations. It was tuned for the ultraviolet laser guide star, while all visible light was sent to HRCam. The atmospheric dispersion was compensated by two rotating prisms inside SAM. The filter transmission curves are given in the instrument manua 4 . We used mostly the Strömgren $y$ filter $(543 / 22 \mathrm{~nm})$ and the nearinfrared $I$ filter.

The pixel scale of HRCam is 15.23 mas. Observation of an object consists in accumulation of 400 frames of $200 \times 200$ pixels each with exposure time of $20 \mathrm{~ms}$ or shorter. Frames of $400 \times 400$ pixels were recorded for pairs with separation larger than 1.'5. Each object was recorded twice and these two image cubes were processed independently. $\mathrm{Pa}$ rameters of resolved binary and triple systems are determined by fitting a model to the power spectrum, as explained in TMH10.

Speckle interferometry of binary stars was carried out serendipitously during five engineering runs of the SAM instrument, from December 2011 to May 2012. These observations used short time periods where the SAM engineering could not be pursued either for technical reasons (hardware failures) or for poor observing conditions (transparent clouds, bad seeing). Cumulative time used by these observations is about one night.

We calibrated the transfer optics of the SAM instrument by imaging a single-mode fiber at the telescope focus. The fiber was translated by a micrometer stage, allowing to accurately determine detector orientation relative to the instrument frame and the physical pixel scale in microns. We rely on the SOAR telescope pointing model and its mechanics to ensure correct orientation of the SAM focal plane on the sky (which however was not checked independently here) and constant scale. Therefore, we refer the position angle to the telescope and use the same pixel scale as in TMH10 and HTM12. Observations of control wide binaries indicate that there are no detectable calibration errors at the level of $<1 \%$ in separation and $1^{\circ}$ in angle. If, in the future, the orbital motion of those wide binaries becomes known with a high accuracy, the present data can be recalibrated post factum.

\subsection{Data tables}

Table 1 lists 158 measures of 121 resolved binary stars and sub-systems, including two new pairs. Its columns contain (1) the WDS designation, (2) the "discoverer designation" as adopted in the WDS, (3) an alternative name, mostly from the Hipparcos catalog, (4) Besselian epoch of observation, (5) filter, (6) number of individual data cubes, $(7,8)$ position angle $\theta$ in degrees (not precessed) and internal measurement error in tangential direction $\rho \sigma_{\theta}$ in mas, $(9,10)$ separation $\rho$ in arcseconds and its internal error $\sigma_{\rho}$ in mas, and (11) magnitude difference $\Delta m$. An asterisk follows the value if $\Delta m$ and the true quadrant are determined from the resolved long-exposure image; a colon indicates that the data are noisy and $\Delta m$ is likely over-estimated (see TMH10 for details). Note that in the cases of multiple stars, the positions and photometry refer to the pairings between individual stars, not with photo-centers of sub-systems.

For stars with known orbital elements, columns

${ }^{4}$ http://www.ctio.noao.edu/new/Telescopes/SOAR/Instruments/SAM(2rdhlye/dfcátrabdepdf list the residuals to the 
ephemeris position and the code of reference to the orbit adopted in VB6 5 References to the orbits revised here are preceded by asterisk; large residuals to those orbits show why the revisions were needed.

Table 2 contains the data on 27 unresolved stars, some of which are listed as binaries in the WDS or resolved here in other filters. Columns (1) through (6) are the same as in Table 1, although Column (2) also includes other names for objects without discoverer designations. Columns $(7,8)$ give the $5 \sigma$ detection limits $\Delta m_{5}$ at 0 '! 15 and $1^{\prime \prime}$ separations determined by the procedure described in TMH10. When two or more data cubes are processed, the best detection limits are listed.

\subsection{New pairs}

11056-1105 = HIP 54214. Gontcharov et al. (2000) discovered photo-center motion with a $30 \mathrm{yr}$ period and a large amplitude of 0 !' 2 , but did not not derive the full set of orbital elements. The faint companion at $0 . \prime 6$ and $60^{\circ}$ is resolved here in the $I$ band, but not in $y\left(\Delta y>6^{m}\right)$. Its position angle roughly matches the plots of that paper. This is an F0V star with fast axial rotation and the Hipparcos-2 (van Leeuwen 2007) parallax $\pi_{\text {HIP }}=16.75 \pm 0.34$ mas. The projected separation of $35 \mathrm{AU}$ and $30 \mathrm{yr}$ period hint at a large mass sum. Gontcharov et al. (2000) suggested that the actual parallax is about 18 mas and that the astrometric companion is massive. Yearly observations will be ideal to follow this interesting system.

11318-2047 = HIP $56245=$ HR 440. A new faint companion at $11^{\prime \prime} 05$ is found here. This is a $\Delta \mu$ astrometric binary according to Makarov \& Kaplan (2005), spectral type F8V, $\pi_{\mathrm{HIP}}=25.98 \pm 0.34$ mas. The projected separation of $40 \mathrm{AU}$ implies orbital period on the order of $\sim 200 \mathrm{yr}$. The companion with $\Delta I=4.9$ must be brighter in the $K$ band, but it was not detected by Boden et al. (2005) when this star served as a calibrator for interferometry.

\section{Updated and new orbits}

In this Section, we derive corrected or first orbits for some pairs observed here. Although cal-

\footnotetext{
${ }^{5}$ See http://ad.usno.navy.mil/wds/orb6/wdsref .html
}

culation of orbital elements is accessible to anyone with a computer, it is still a challenging task when the measures are scarce and their interpretation is ambiguous (erroneous measures or quadrant flips). Additional help is provided by the availability of Hipparcos parallaxes, allowing to reject tentative orbits with improbably large or small mass sum. On the other hand, motion in a visual orbit affects Hipparcos reductions and should be included in the astrometric solution whenever possible; otherwise the parallax and proper motion can be biased (Shatskii \& Tokovinin 1998; Soderhjelm 1999).

The focus here is on fast-moving pairs where new observations allow a substantial progress, as in HTM12 where 42 orbits were computed. We refrain from correcting orbits with large current separations. Of 15 orbits presented in Table 3, eight are corrections of prior orbits, two are drastic revisions, five are new. Final orbital elements are obtained by least-squares fitting with weights inversely proportional to the squares of observational errors. The errors of visual measures are assumed to be 0. . 05 , speckle interferometry at 4$\mathrm{m}$ telescopes is assigned errors of 2 mas, with few exceptions such as uncertain measures marked by colons in INT4 and obvious outliers. The much larger weight of speckle measures enforces their good fit to the orbit. For some preliminary orbits where the least-squares fits did not converge, we fixed one or more elements (marked by asterisk instead of formal error). Considering that errors of the input data do not obey the Gaussian statistics, formally derived errors of orbital elements and goodness-of-fit criteria such as $\chi^{2}$ should be taken with reservation, as order-of-magnitude estimates at best. Table 3 also gives orbital grades in the system adopted by VB6 (1 - definitive, 4 preliminary).

Figures 1 to 4 present orbits in the plane of the sky, in standard orientation (North up, East left) with scale in arcseconds. The primary components at coordinate center are marked by large asterisks. The orbits are plotted in full line, the prior orbits in dashed line where appropriate. The measures (empty squares for visual, filled squares for speckle) are connected to their positions on the orbit. Non-resolutions are shown by connecting predicted positions of the secondary to the coordinate origin. Some dates of speckle measures are shown. 
Table 4 lists astrophysical parameters of pairs with new orbits. Columns (1) and (2) repeat the WDS and HIP identifies, column (3) lists the trigonometric parallax and its error from van Leeuwen (2007). The spectral type in column (4) and combined visual magnitude $V$ in column (5) are taken from SIMBAD, the magnitude difference in the Hipparcos band $\Delta \mathrm{Hp}$ in column (6) is compared to $\Delta y$ from speckle photometry in column (7). When several measures of $\Delta y$ are available, we select the best one (widest separation) and round it to the nearest $0 .{ }^{\mathrm{m}} 1$.

The last four columns of Table 4 recall the orbital period $P$ and give estimates of component masses $M_{1}$ and $M_{2}$ and the dynamical parallax $\pi_{\text {dyn }}$. Individual magnitude of the components are computed from $V$ and $\Delta \mathrm{Hp}$. When the Hipparcos differential photometry is missing or considered unreliable (marked by colons), $\Delta y$ is used instead. Masses of the components are found from the standard relation with absolute $V$-magnitude (Lang 1992) using those magnitudes and the Hipparcos distance modulus. Then the dynamical parallax is computed from the mass sum and orbital elements $P, a$. With this parallax, the masses are estimated again and the process is iterated to convergence. These estimates of mass and parallax based on standard relations for main sequence stars should not be mistaken for direct measurements, but can be useful for statistics; no meaningful errors can be assigned. When the dynamical and Hipparcos parallaxes match and the mass estimates correspond to the spectral type, it is a good indication that the data are mutually consistent.

06359-3605 = RST 4816 Ba,Bb. The new orbit with $14 \mathrm{yr}$ period is radically different from the 28.5 yr orbit of Cvetkovic (2008), but closer to the three solutions proposed by Branham (2009). Large part of the orbit remains unobserved. This pair forms a physical quadruple with another binary HIP 31509 = FIN 19 Aa,Ab, also measured here.

07518-1354 = BU 101. This is a minor revision of the orbit by Pourbaix (2000) needed to reduce its large residual from our measure in 2009. Radial velocities (RVs) from the above paper were included in the combined orbital solution, but make little influence on the final elements which are primarily constrained by speckle interferometry. The orbit is now extremely well de- fined.

08270 $-\mathbf{5 2 4 2}=\mathrm{B}$ 1606. The orbit by Finsen (1963) is revised here using the three available speckle measures, leading to a more accurate period and to the reduced orbit size. Systematic over-estimation of the separation by Finsen's visual interferometry is apparent in Figure 1c.

08345-3236 = FIN 335. We confirm and slightly correct the orbit by Soderhielm (1999). The $17.35 \mathrm{yr}$ period is very well defined now, but further coverage by speckle is still needed. The system is evolved, judging from its luminosity, estimated masses, and spectral type G5IV. The speckle $\Delta y$ is very consistent and preferred to $\Delta \mathrm{Hp}$.

09173-6841= FIN 363 AB has an unusually short period of only $3.44 \mathrm{yr}$. The Hipparcos photometry is doubtful because of close 0 "! 1 separation.

11009-4030 $=$ FIN 365. The latest measure contradicts the first orbit published in HTM12, which in fact predicts an unrealistically small mass sum. We propose here an alternative orbit with retrograde motion which reproduces the nonresolutions by Finsen in 1963-1966 (Figure 1f) and corresponds to a reasonable mass sum. Double lines were noted by Nordström et al. (2004). The star appears to be evolved. The Hipparcos parallax could be affected by the orbital motion unaccounted for in its data reduction.

$\mathbf{1 1 1 9 0 + 1 4 1 6}=\mathrm{STF} 1527$ has a long orbital period of $415 \mathrm{yr}$, but it moved fast through the periastron in 2009-2012, allowing us to compute a better orbit. The recent orbit revision by Scardia et al. (2011) with $P=551 \mathrm{yr}$ is not yet included in VB6.

$\mathbf{1 1 2 1 0}-\mathbf{5 4 2 9}=\mathbf{I} \mathbf{8 7 9}=\pi$ Cen. The orbit by Mason et al. (1999) had to be revised using our measures near the periastron. The high eccentricity $e=0.853$ is now well established.

12357-1650 = FIN $368 \mathrm{Aa}, \mathrm{Ab}$ is the first orbit determination. Speckle measures of 1989 91 and 2009-11 repeat themselves, hinting at $20 \mathrm{yr}$ period. However, the measure by Mason et al. in 2006.2 does not fall on the same ellipse and had to be ignored. It could refer to another star, as FIN 368 should have been unresolved at that time according to our preliminary orbit, which also matches the speckle non- 

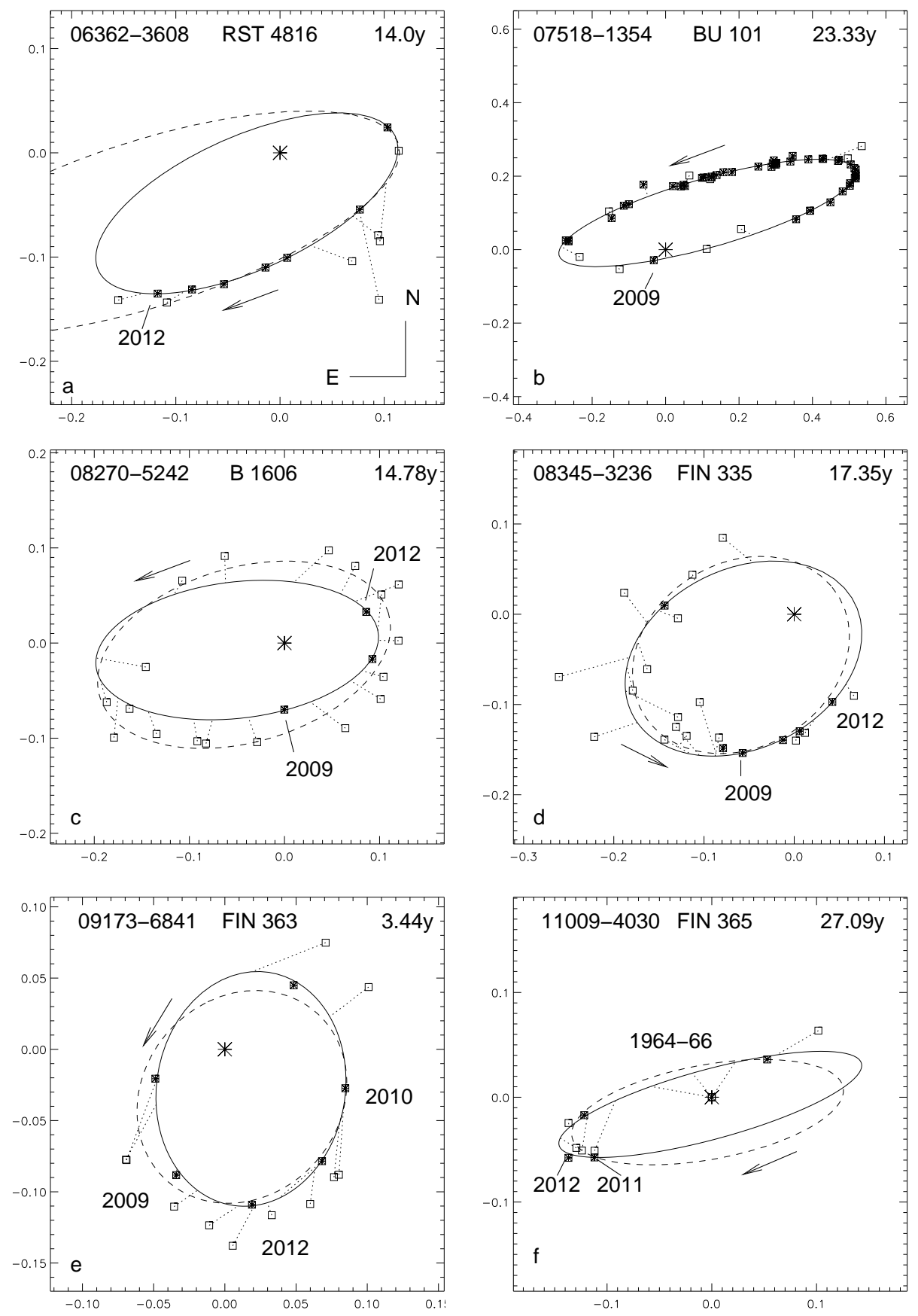

Fig. 1.- New orbits (I). See text. 

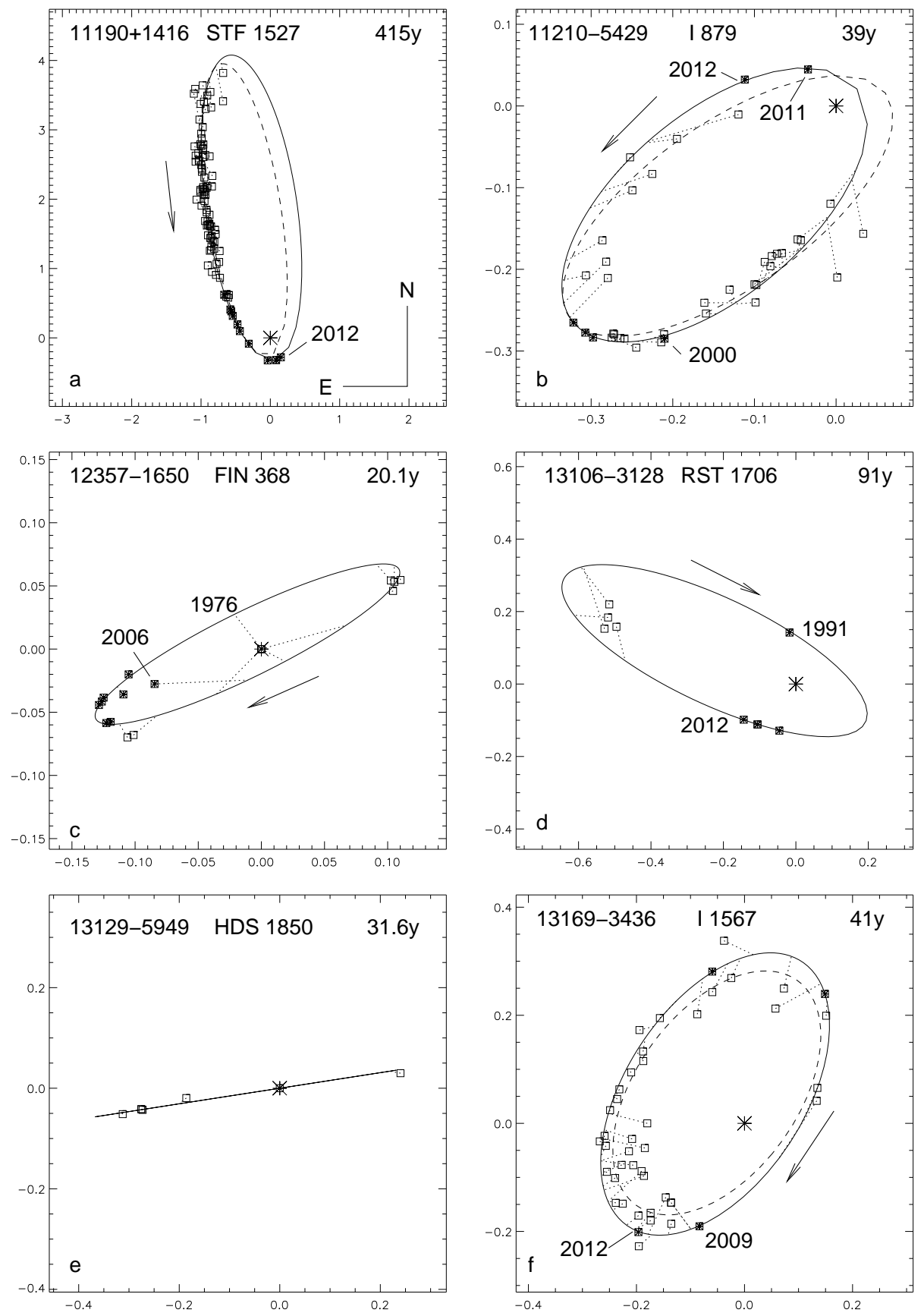

Fig. 2.- New orbits (II). 

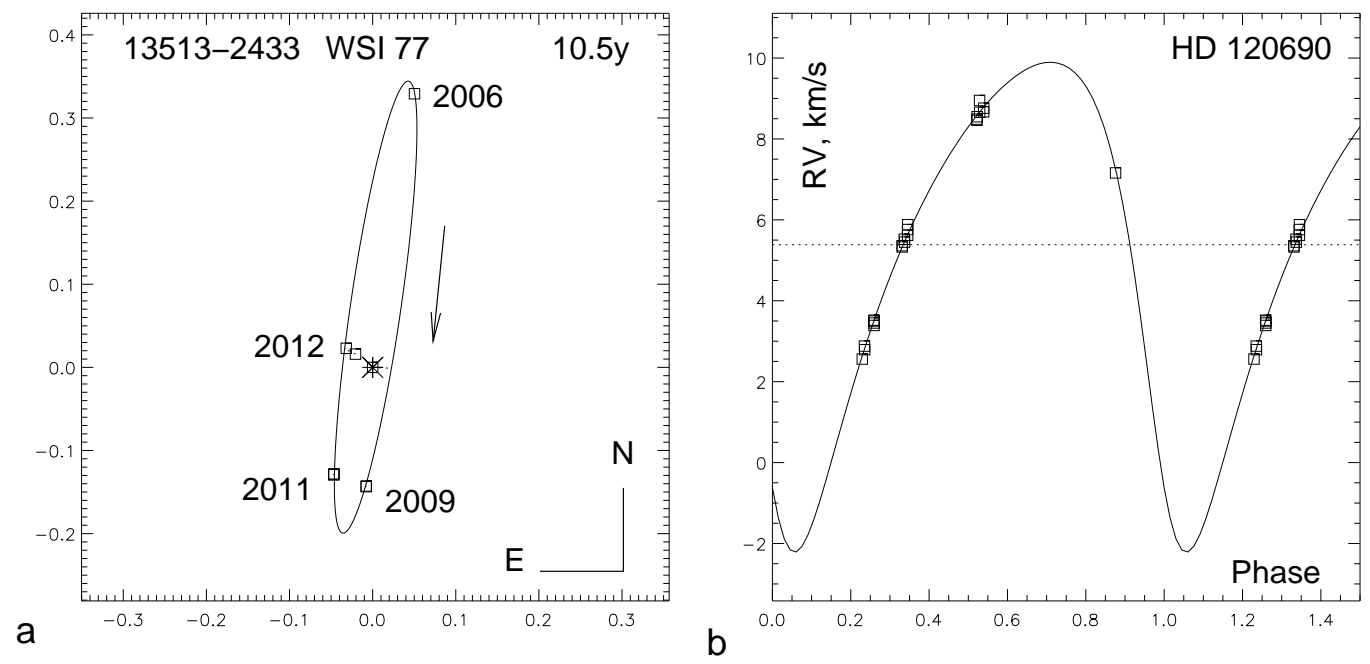

Fig. 3.- New orbits (III): the combined orbit of WSI $77=$ HD 120690. Speckle measures are plotted on the left (a), radial velocities on the right (b).
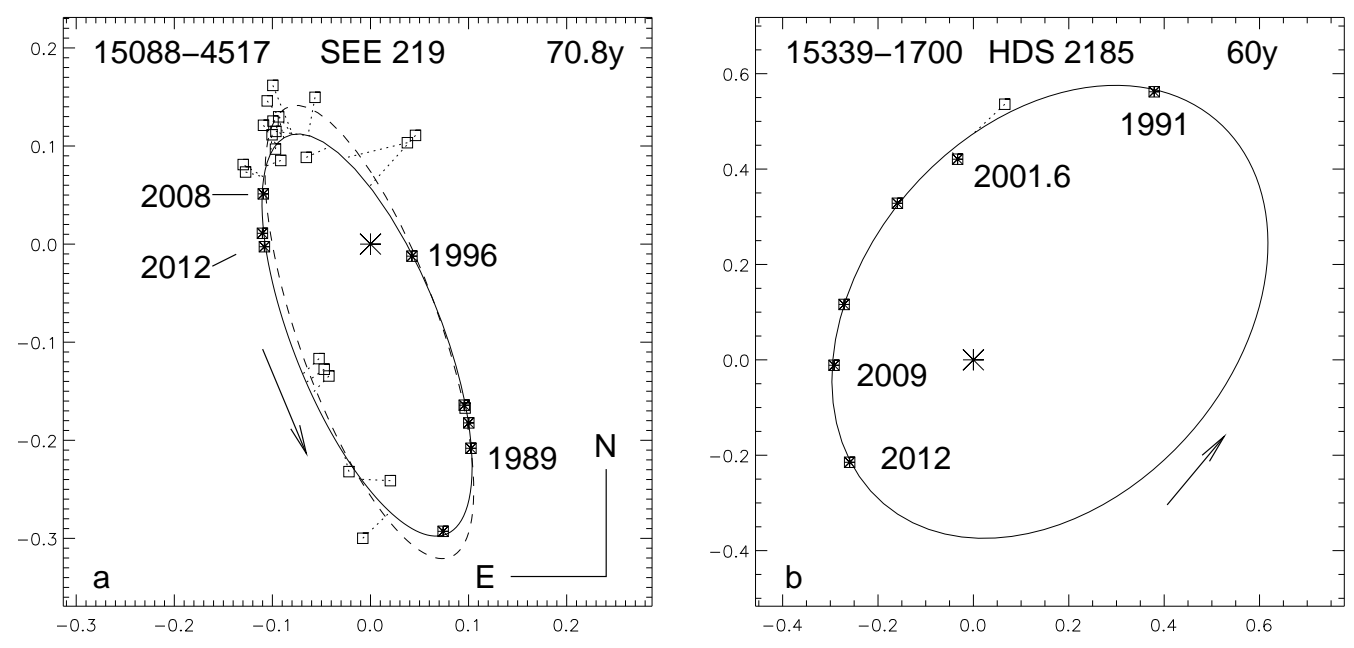

Fig. 4.- New orbits (IV). 
resolution in 1976.3 and the non-resolutions in 1964-1966 by Finsen. An alternative orbit with $P=10.13 \mathrm{yr}$ and $e=0.9$ can also be fitted to the data. The Hipparcos measure on 1991.25 contradicts speckle interferometry on 1991.39; it had to be ignored. Nordström et al. (1997) noted double lines broadened by fast axial rotation of $100 \mathrm{~km} \mathrm{~s}^{-1}$ and $20 \mathrm{~km} \mathrm{~s}^{-1}$. However, individual RVs measured by these authors during 1987-1991 (near the apastron) do not show any systematic behavior that could be related to the orbit. Continued speckle monitoring will be critical for confirming the orbit. The tertiary companion B at $11^{\prime \prime} 8$ is physical.

13106-3128 = RST 1706 is an example of a neglected binary discovered by R. A. Rossiter in 1934 but observed so rarely that only now, after a nearly full revolution, the first orbit could be proposed.

13129-5949 = HDS $1850=$ HR 4980 has a tentative edge-on first orbit with $P=31.6 \mathrm{yr}$. This is a chromospherically active G0V dwarf and a ROSAT X-ray source. There are at least four components in the system: Aa1,Aa2 is a doublelined spectroscopic and eclipsing binary with $4.2 \mathrm{~d}$ period, $\mathrm{Aa}, \mathrm{Ab}$ is the pair considered here, and the visual companion B at $25^{\prime \prime} .5$ is physical. The orbits of Aa1,Aa2 and Aa,Ab may be co-planar.

13169-3436 = I 1567 has a well-established orbit by Heintz (1986) which is corrected here to better match the new speckle data. Heintz notes that this pair is a "puzzling case" because of some very discordant historical measures; these deviant points were omitted from Figure $2 \mathrm{f}$ and ignored in the calculation.

13513-2433 = WSI $77=$ HD 120690 is a chromospherically active G5 dwarf within 20 pc from the Sun. According to Abt \& Willmarth (2006), it is also a single-lined spectroscopic binary with $10.3 \mathrm{yr}$ period. We used RVs from that work and the average RV from Nidever et al. (2002) together with four speckle points for the combined orbital solution presented in Figure 3. The spectroscopic elements are $K_{1}=6.06 \pm 0.25 \mathrm{~km} \mathrm{~s}^{-1}$ and $V_{0}=5.38 \pm 0.10 \mathrm{~km} \mathrm{~s}^{-1}$, the rms residual in $\mathrm{RV}$ is $0.11 \mathrm{~km} \mathrm{~s}^{-1}$. The node $\omega$ listed in Table 3 corresponds to the primary component, therefore $\Omega$ was chosen to describe the secondary's relative motion. The pair was "caught" at close separation in 2012 .
15088-4517 = SEE $219 \mathrm{AB}=\lambda$ Lup is a B3V binary belonging to the Sco-Cen association. A minor revision of the orbit by Docobo \& Ling (2007) proposed here turns it into a definitive one, with both sides of the ellipse now covered by speckle measures and one full revolution observed (Figure 4a). The Hipparcos parallax corresponds to an uncomfortably large mass sum. The true parallax should be around 6 mas, matching the distance to the association.

15339-1700 = HDS 2185 has its first $60 \mathrm{yr}$ orbit determined here, with nearly half of it covered (Figure 4b). The orbit is still preliminary. The speckle measure on 2001.56 was given a lower weight.

\section{Other results}

\subsection{Astrometric binaries}

The Hipparcos satellite detected accelerated proper motion $\dot{\mu}$ in some stars (ESA 1997). Accelerated motion is also inferred from the difference $\Delta \mu$ between Hipparcos short-term proper motion and ground-based catalogs (Makarov \& Kaplan 2005; Frankowski et al. 2007). These astrometric observables do not constrain orbital periods and mass ratios, therefore direct resolution and follow-up with adaptive optics and speckle interferometry is needed. Such work has been started recently (Tokovinin et al. 2012). We continue to follow astrometric binaries, collecting data for eventual orbit calculation. The list of 15 such systems observed here (including 5 unresolved) is given in Table 5 .

Astrometric orbits for HIP 38146, 38414, 46396, and 84924 are published. However, they are inaccurate and do not match speckle measures in position angle. With few more measures it will be possible to determine true visual orbits, but so far this appears premature. For the remaining resolved pairs the separation and parallax are used to estimate order-of-magnitude orbital periods. The two newly resolved astrometric pairs are commented in Section 2.3. HIP 64006 shows elongation at $77^{\circ}$ indicative of its partial resolution, unless caused by vibrations or other artifacts; we do not consider this resolution secure. Estimated mass ratio of HIP 84494 is 0.3 , semi-major axis 0 .'06, therefore the companion is below detection limit. 


\subsection{Spurious or enigmatic pairs}

Binaries may be unresolved temporarily when their orbital motion makes them too close. However, repeated non-resolutions of a binary with a short estimated period put in doubt its veracity. For example, some CHARA speckle pairs were later retracted by McAlister et al. (1993). Artifacts that may lead to such spurious discoveries

(a)

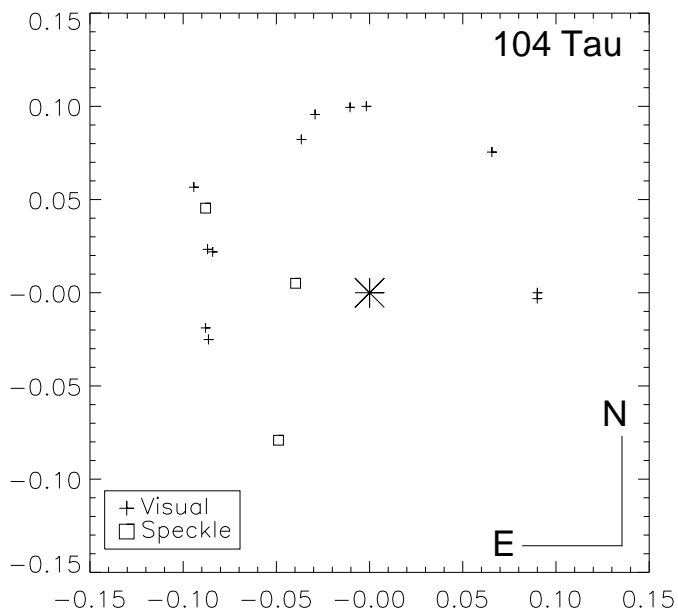

(b)

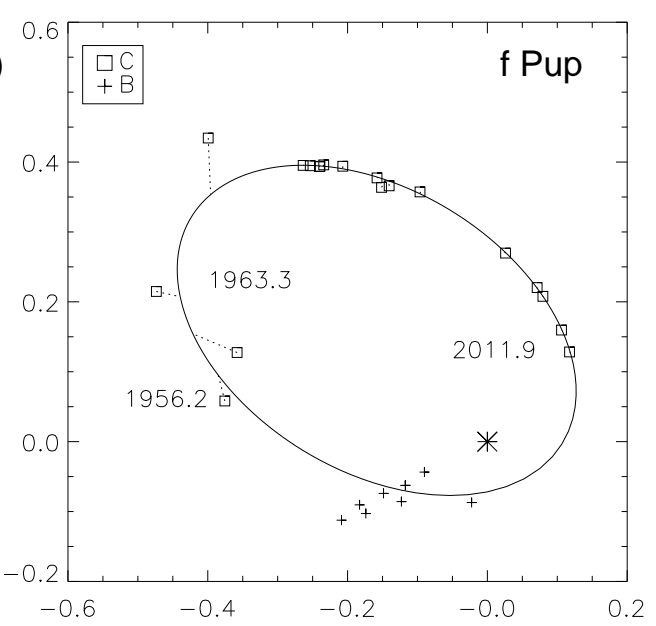

Fig. 5.- Top (a): motion on the sky of 104 Tau. Visual observations are plotted as crosses, speckle measures as squares. Bottom (b): f Pup = FIN 324 AC (elliptical orbit connected to squares) and measures of AB (crosses). The scale on both plots is in arcseconds. are discussed in TMH10.

In some cases, however, binaries were observed on multiple occasions by different people before disappearing. It is difficult to "write off" these binaries as spurious; rather, they may point to some new phenomena. Such "ghost" binaries are brought to light here. We do not propose any explanation; the purpose is to attract attention and to stimulate further collection of data on those stars. Table 6 lists close binaries and sub-systems which were repeatedly unresolved in recent speckle runs at SOAR. It also gives $\pi_{\text {HIP }}$, spectral type, and $V$ magnitude. Comments on individual stars follow.

$05074+1839=104$ Tau is a G4V dwarf at $16 \mathrm{pc}$ resolved into equal components at 0.1 by R. Aitken in 1912. The WDS contains 16 resolutions of this pair (Figure 5, top). Apart from Aitken himself, it has been resolved on multiple occasions by R.H. Wilson in 1934-1971, by W. Finsen (1953-1955) and by others, although in other instances those observers found it to be single. The measures plotted in Figure 5 a suggest a nearcircular orbit seen face-on with a semi-major axis on the order of $0 . \prime 1$ or $1.5 \mathrm{AU}$. Assuming a mass sum of $2 M_{\odot}$, the orbital period should be around $1.3 \mathrm{yr}$; in fact, two orbits with periods $1.19 \mathrm{yr}$ and 2.38 yr were published by Eggen (1956). This binary should be an easy target for speckle interferometry at 4-m telescopes. It was observed 10 times from 1976.9 to 1980.7 with speckle and, surprisingly, found unresolved on all occasions, excluding any short-period orbits. Later, however, two measures were made by the author at 1-m telescope with a phase-grating interferometer. The first resolution in 1984.8 at 0. .04 was tentative (below the diffraction limit), but the second one in 1985.7 was secure, being average of two observations. It was followed by the speckle resolution at 4-m telescope in 1988.17, after which the pair disappeared again. It was found unresolved in 2012 (Figure 6).

The star is well studied. Two statistical surveys of binaries within $25 \mathrm{pc}$ consider it to be single (Duquennoy \& Mayor 1991; Raghavan et al. 2010). Heintz \& Borgman (1984) state that measures cannot be fitted by any orbit and conclude: "Although this alleged visual binary (ADS 3701) has three published orbits, it is probably spurious". Several independent RV studies have shown that this star is not a spectroscopic binary. Pre- 
cise RVs measured by Nidever et al. (2002) are stable to better than $100 \mathrm{~m} \mathrm{~s}^{-1}$ over 388 days, excluding orbital periods from one to two years with high confidence. Data with lower precision show a constant RV of $+21 \mathrm{~km} \mathrm{~s}^{-1}$ over many years (Duquennov \& Mavor 1991; Abt \& Willmarth 2006; Raghavan et al. 2010).

The star is located about $1^{m}$ above the main sequence, supporting the thesis of an equalcomponent binary. If the orbit is seen face-on, the RV variation would be small, especially if the components are of equal brightness (blended lines move in opposite directions, the centroid stays constant). However, the lines in this star remain narrow and the speckle non-resolution during $3.8 \mathrm{yr}$ firmly excludes a face-on orbit. Remember that 104 Tau is bright (no identification errors possible) and that the components are supposedly equally bright, hence easy to resolve by speckle.

If this star is single (as everything seems to suggest), we cannot dismiss its multiple resolutions with micrometer, eyepiece interferometer, and speckle as spurious; occasional image doubling (or at least elongation) must be real.

07374-3458 is the bright star f Puppis (HR 2937, HIP 37096, HD 61330). It was resolved as $0^{\prime \prime} \cdot 2$ binary FIN $324 \mathrm{AB}$ in 1954.31 by Finsen (1956) using double-slit interferometer at the $0.7 \mathrm{~m}$ Innes refractor. The components were comparable in brightness with $\Delta m$ from 0.3 to 0.6. Finsen published 7 mean positions resulting from 25 nights (the last one in 1960.26). His measures show considerable scatter (crosses in Figure 5b); the motion of $\mathrm{AB}$ looks erratic rather than regular.

Finsen could not resolve AB since 1960.29, despite repeated attempts. However, on 1963.305 he found another companion $\mathrm{C}$ at 0.52 with $\Delta m=$ 0.8. In fact W.H. van den Bos saw both companions earlier and measured $\mathrm{AB}$ and $\mathrm{AC}$ simultaneously in 1956.2 and 1959.7 (van den Bos 1957, 1961). The pair AC was measured later by R.H. Wilson, Hipparcos, and various speckle interferometers. All speckle observations show no trace of the subsystem AB, except the one on 1989.305 where B looks doubtful and much fainter than C (Mason 2011). No trace of B was seen at SOAR in 2008-2011 (4 speckle runs).

The binary system AC follows a Keplerian orbit with 81 yr period (HTM12) which was slightly
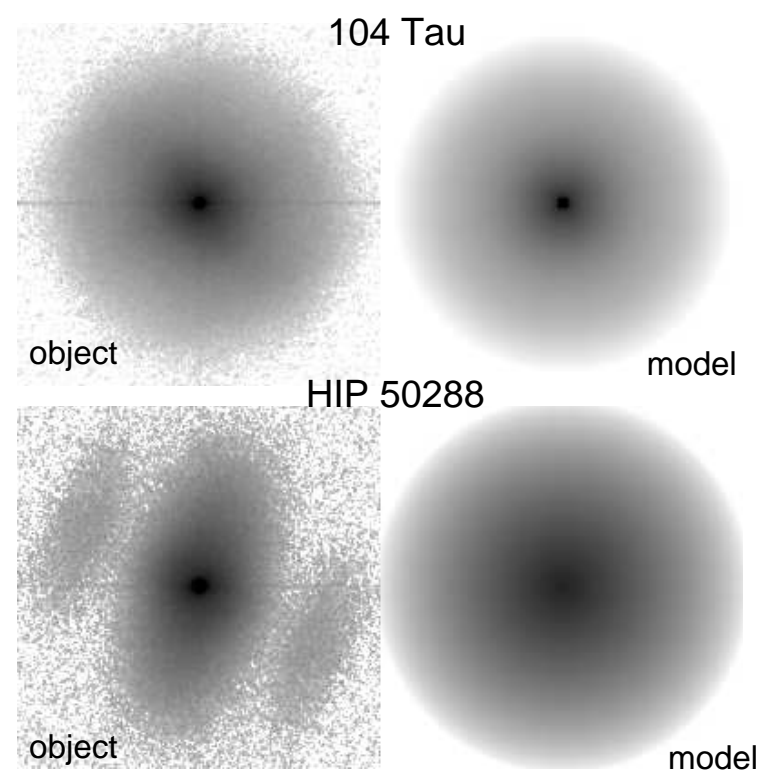

Fig. 6.- The power spectrum of 104 Tau recorded at SOAR on 2012.0253 in the $y$ filter (top) shows no sign of fringes (left side - data, right side their model for a single star). The gray levels display power on negative logarithmic scale from $10^{-7}$ (white) to $10^{-3}$ (black). For comparison, the power spectrum of resolved binary HIP 50288 $(0 \prime \prime 035, \Delta y=0.8)$ recorded with the same equipment on 2012.0258 is shown in the bottom. 
corrected here using the latest measure. This excludes confusion between the companions (i.e. B and $\mathrm{C}$ being the same star). Besides, both companions were measured concurrently by van den Bos.

The companion B cannot be real. The closest separation of AC is 0 .' 09 according to the orbit and excludes any sub-system with comparable separation because such a triple star would be dynamically unstable. The fact that the orbit of $\mathrm{AC}$ is known does not allow us to explain the apparent non-hierarchical configuration by projection. If $\mathrm{B}$ were real, its orbital period would be on the order of $10 \mathrm{yr}$ (scaling from the orbit of AC) and it would have shown up in our speckle data. Like $104 \mathrm{Tau}$, we have here a binary AB which actually is not a binary - a "ghost".

09125-4337 = FIN $317 \mathrm{Aa}, \mathrm{Ab}$ is a close sub-system in the 2.9 pair $\mathrm{AB}=\mathrm{HJ}$ 4188. After discovery of $\mathrm{Aa}, \mathrm{Ab}$ in 1951 at 0 "'116, Finsen (1951) was unable to resolve the star again on twelve occasions till 1968, except one other tentative measure in 1962. Yet the object was resolved by speckle in 1989.94 at 0.144 and in 2006.18 at 0 '.123. Despite orbital period of $\sim 50 \mathrm{yr}$ estimated from projected separation, the sub-system was not detected in 3 runs at SOAR (2009-2012), while the wider pair AB was measured. This may be yet another case of erratic measures and non-resolutions.

15462-2804 = HR $5856=$ HD 140722. The binary companion B discovered by S.W. Burnham in 1878 moved since then by $+6^{\circ}$ in angle, now at $0 . \prime 63$ separation. Considering this slow motion, the pair is likely much wider than it seems, being seen in projection. The sub-system CHR 50 $\mathrm{Aa}, \mathrm{Ab}$ was discovered by speckle interferometry in 1983.42 at 0.20 (McAlister et al. 1987). A total of four measures are listed in the INT4 catalog, the last one in 2006.19. Curiously, the wide pair AB was measured with speckle at 4-m telescopes several times (in 1985.50, 1989.31, 1991.39) without resolving the sub-system. We measured the $\mathrm{AB}$ and found no trace of CHR 50 in three runs at SOAR in 2009-2012. The separation of CHR 50 implies an orbital period of $\sim 50 \mathrm{yr}$. Yet the few speckle resolutions show a fast motion or a random scatter. If the sub-system CHR 50 were real, we would expect it to cause some wobble in the motion of $\mathrm{AB}$, but no such signal is seen.

$\mathbf{1 5 4 6 7 - 4 3 1 4}$ is a G5V dwarf at 47 pc. The
WDS catalog notes its resolution in 1926 by Innes at $0^{\prime \prime} .3$ and the last measure in 1935 . The separation corresponds to an orbital period of $\sim 50 \mathrm{yr}$. Yet the system was not resolved by Hipparcos in 1991.25 and by speckle in 2001.56, 2008.54, and 2012.18. Nordström et al. (2004) found only a marginal variability of RV during $8 \mathrm{yr}$. The binarity is thus questionable.

\section{Conclusions}

This work provides follow-up measures of close binary stars to be used in calculation or refinement of their orbits. Fifteen orbits are contributed to the VB6 catalog. Speckle interferometry is very efficient. Only a modest investment of telescope time (few nights per year at $4-\mathrm{m}$ telescopes) is needed to supply good-quality speckle measures for calculating orbits of fast binaries and making the existing orbits accurate and definitive. Bright stars can be observed in twilight or through transparent clouds.

One class of objects to benefit from the speckle follow-up are Hipparcos astrometric binaries, mostly nearby low-mass dwarfs. Two such stars are resolved here for the first time, few more are measured. Astrometry of these and other binaries requires knowledge of their orbits to disentangle them from parallax and PM. Future space astrometric missions like Gaia will be too short to do this and will rely heavily on the VB6 catalog. This is one more reason to follow the motion of fast binaries with speckle interferometry now.

Determination of a large number of orbits is a routine task. However, any large sample contains unusual or particularly interesting objects. This might be the case of "ghost" binary companions that have been resolved several times, yet seem non-existent. Here we attract attention to two such cases, 104 Tau and f Pup, and to some other visual companions with seemingly erratic motion and frequent disappearances. It is difficult to accept that these resolutions, some by very accomplished observers, are all spurious. Continued monitoring of such "ghosts" is needed in hope of collecting crucial observations and eventually explaining this phenomenon.

We thank the operators of SOAR D. Maturana, S. Pizarro, P. Ugarte, A. Pastén for their 
help with labor-intensive speckle observations, B. Mason and W.I. Hartkopf - for sharing archival auto-correlation of FIN 324, extracting data from the WDS, and commenting the draft of this paper. This work used the SIMBAD service operated by Centre des Données Stellaires (Strasbourg, France), bibliographic references from the Astrophysics Data System maintained by SAO/NASA, and the Washington Double Star Catalog maintained at USNO. Comments by anonymous Referee helped to improve the presentation.

Facilities: SOAR.

\section{REFERENCES}

Abt, H. A. \& Willmarth, D. 2006, ApJS, 162, 207

Boden, A. F., Sargent, A. I., Akeson, R. L. et al. 2005, ApJ, 635, 442

Branham, R. L. 2009, A\&A, 507, 1107

Cvetkovic, Z. 2008, IAU Inf. Circ. Double Stars, 164

Docobo, J. A. \& Ling, J. F. 2007, AJ 133, 1209

Duquennoy, A., Mayor, M. 1991 A\&A, 248, 485

Eggen, O. J. 1956, AJ, 61, 405

ESA 1997, The Hipparcos and Tycho Catalogues, ESA SP-1200 (Nordwijk, Netherlands: ESA Publication Division)

Finsen, W. S. 1956, Union Obs. Circ., 6, 94

Finsen, W. S. 1956, Union Obs. Circ., 6, 259

Finsen, W. S. 1963, Republic Obs. Circ., 122, 41

Frankowski, A., Jancart, S., \& Jorissen, A. 2007, A\&A, 464, 377

Goldin, A. \& Makarov, V. V. 2007, ApJS, 173, 137

Gontcharov, G. A., Andronova, A. A., \& Titov, O. 2000, A\&A, 355, 1164

Hartkopf, W. I., Mason, B. D. \& Worley, C. E. 2001, AJ, 122, 3472 (VB6)

Hartkopf, W. I., Tokovinin, A., Mason, B. D. 2012, AJ, 143, 42 (HTM12)

Heintz, W. D. \& Borgman, E. R. 1984, AJ, 89, 1068
Heintz, W. D. 1986, A\&AS, 64, 1

Jancart, S., Jorrisen, A., Babusiaux, C., \& Pourbaix, D. 2005, A\&A, 442, 365

Kennedy, G. M., Wyatt, M. C., Sibthorpe, B. et al. 2012, MNRAS, 420, 2264

Lang, K. R. 1992, Astrophysical data. Planets and Stars (Berlin: Springer-Verlag)

Makarov, V. V. \& Kaplan, G. H., 2005, AJ, 129, 2420 (MK05)

Mason, B. D., Douglass, G. G., \& Hartkopf, W. I. 1999, AJ, 117, 1023

Mason, B. D., Wycoff, G. L., Hartkopf, W. I. et al. 2001, AJ, 122, 3466 (WDS)

Mason, B. D. 2011, private communication

McAlister, H. A., Hartkopf, W. I., Hutter, D. J., \& Franz, O. G. 1987, AJ, 93, 688

McAlister, H. A., Mason, B. D., Hartkopf, W. I., \& Shara, M. M. 1993, AJ, 106, 1639

Nidever, D. L., Marcy, G. W., Butler, R. P. et al. 2002, ApJS, 141, 503

Nordström, B., Steranik, R. P., Latham, D. W., \& Andersen, J. 1997, A\&AS, 126, 21

Nordström, B., Mayor, M., Andersen, J. et al. 2004, A\&A, 418, 989

Pourbaix, D. 2000, A\&AS, 145, 215

Prieur, J.-L., Scardia, M., Pansecchi, L. et al., 2009, MNRAS, 395, 907

Raghavan, D., McAlister, H. A., Henry, T. J. et al. 2010, ApJS, 190, 1

Roberts, L.C ., Turner, N. H., ten Brummelaar, T. A. et al. 2011, AJ, 142, 175

Scardia, M., Prieur, J.-L., Pansecchi, L., \& Argyle, R. W. 2011, IAU Inf. Circ. Double Stars, 175

Shatskii, N. I. \& Tokovinin, A. A. 1998, Aston. L, 24,673

Soderhjelm, S. 1999, A\&A, 341, 121

Tokovinin A., Tighe R., Schurter P. et al. 2008, Proc. SPIE, 7015, 157 
Tokovinin, A. \& Cantarutti, R. 2008, PASP, 120, 170

Tokovinin, A., Mason, B. D., \& Hartkopf, W. I. 2010, AJ, 139, 743 (TMH10)

Tokovinin, A. Cantarutti, R., Tighe, R. et al. 2010, PASP, 122, 1483 (SAM09)

Tokovinin, A., Hartung, M., Hayward, Th. L., \& Makarov, V. V. 2012, AJ, in press.

van den Bos, W.H. 1957, Union Obs. Circ. 6, 291

van den Bos, W.H. 1961, Union Obs. Circ. 6, 353

van Leeuwen, F. 2007, A\&A, 474, 653

This 2-column preprint was prepared with the AAS IATEX

macros v5.2. 
TABLE 1

Measurements of Binary Stars at SOAR

\begin{tabular}{|c|c|c|c|c|c|c|c|c|c|c|c|c|c|}
\hline $\begin{array}{c}\text { WDS } \\
(2000)\end{array}$ & $\begin{array}{l}\text { Discoverer } \\
\text { Designation }\end{array}$ & $\begin{array}{l}\text { Other } \\
\text { name }\end{array}$ & $\begin{array}{c}\text { Epoch } \\
+2000\end{array}$ & Filt & $\mathrm{N}$ & $\begin{array}{c}\theta \\
(\mathrm{deg})\end{array}$ & $\begin{array}{l}\rho \sigma_{\theta} \\
(\mathrm{mas})\end{array}$ & $\begin{array}{l}\rho \\
\left(^{\prime \prime}\right)\end{array}$ & $\begin{array}{c}\sigma \rho \\
(\mathrm{mas})\end{array}$ & $\begin{array}{c}\Delta m \\
(\mathrm{mag})\end{array}$ & $\begin{array}{c}{[\mathrm{O}-\mathrm{C}]_{\theta}} \\
(\mathrm{deg})\end{array}$ & $\begin{array}{c}{[\mathrm{O}-\mathrm{C}]_{\rho}} \\
\left({ }^{\prime \prime}\right)\end{array}$ & $\begin{array}{l}\text { Reference } \\
\text { VB6 code }\end{array}$ \\
\hline $06003-3102$ & HU 1399 AB & HIP 28442 & 11.9353 & $\mathrm{y}$ & 2 & 113.5 & 0.4 & 0.6945 & 0.3 & 1.2 & -1.5 & 0.014 & Tok2005 \\
\hline \multirow{2}{*}{$06359-3605$} & FIN $19 \mathrm{Aa}, \mathrm{Ab}$ & HIP 31509 & 11.9353 & $\mathrm{y}$ & 2 & 351.5 & 0.1 & 0.2824 & 0.1 & 1.3 & 0.8 & -0.001 & Hrt2011d \\
\hline & & & 12.1839 & $\mathrm{y}$ & 2 & 350.3 & 0.0 & 0.2887 & 0.3 & 1.2 & 0.2 & 0.000 & Hrt2011d \\
\hline \multirow[t]{2}{*}{$06359-3605$} & RST $4816 \mathrm{Ba}, \mathrm{Bb}$ & HIP 31547 & 11.9353 & $\mathrm{y}$ & 2 & 139.0 & 0.1 & 0.1791 & 0.1 & 0.8 & 33.5 & -0.180 & ${ }^{*}$ Cve $2008 b$ \\
\hline & & & 12.1839 & $\mathrm{y}$ & 2 & 136.4 & 0.0 & 0.1849 & 0.1 & 0.7 & 31.3 & -0.169 & ${ }^{*}$ Cve $2008 b$ \\
\hline $07187-2457$ & FIN $313 \mathrm{Aa}, \mathrm{Ab}$ & HIP 35415 & 11.9353 & $\mathrm{y}$ & 2 & 128.8 & 1.4 & 0.1181 & 2.0 & 0.9 & & & \\
\hline $07187-2457$ & TOK $42 \mathrm{Aa}, \mathrm{E}$ & HIP 35415 & 11.9353 & $\mathrm{y}$ & 2 & 88.1 & 1.2 & 0.9454 & 0.4 & 4.4 & & & \\
\hline $07294-1500$ & STF $1104 \mathrm{AB}$ & HIP 36395 & 11.9353 & $\mathrm{y}$ & 2 & 34.4 & 0.6 & 1.8309 & 0.4 & $1.3 *$ & -1.8 & 0.200 & WSI2004a \\
\hline \multirow[t]{2}{*}{$07374-3458$} & FIN 324 AC & HIP 37096 & 11.9353 & $\mathrm{y}$ & 2 & 317.5 & 0.0 & 0.1740 & 0.2 & 1.6 & 1.5 & -0.000 & Hrt2012a \\
\hline & & & 11.9353 & $\mathrm{H} \alpha$ & 2 & 317.6 & 0.2 & 0.1742 & 0.6 & 1.8 & 1.6 & 0.000 & Hrt2012a \\
\hline $07456-3410$ & TOK $193 \mathrm{Aa}, \mathrm{Ab}$ & HIP 37853 & 11.9353 & $\mathrm{y}$ & 2 & 72.1 & 1.4 & 0.3098 & 1.6 & 4.0 & & & \\
\hline $07479-1212$ & STF 1146 & HIP 38048 & 12.1019 & $\mathrm{y}$ & 2 & 342.1 & 0.2 & 1.1457 & 0.6 & $1.4 *$ & 0.2 & 0.108 & Nov2007d \\
\hline $07490-2455$ & TOK 194 & HIP 38146 & 11.9353 & $\mathrm{H} \alpha$ & 2 & 155.1 & 1.3 & 0.0512 & 3.7 & 1.7 & & & \\
\hline \multirow[t]{3}{*}{$07518-1354$} & BU 101 & HIP 38382 & 12.0254 & $\mathrm{y}$ & 2 & 288.2 & 0.1 & 0.5077 & 0.2 & 0.9 & -1.4 & -0.029 & ${ }^{*} \mathrm{Pbx} 2000 \mathrm{~b}$ \\
\hline & & & 12.1019 & $\mathrm{y}$ & 2 & 288.4 & 0.1 & 0.5134 & 0.1 & 1.1 & -1.3 & -0.026 & *Pbx2000b \\
\hline & & & 12.1019 & I & 2 & 288.4 & 0.1 & 0.5135 & 0.2 & 0.9 & -1.4 & -0.026 & *Pbx2000b \\
\hline $07522-4035$ & TOK 195 & HIP 38414 & 11.9354 & $\mathrm{H} \alpha$ & 2 & 168.4 & 2.7 & 0.0442 & 2.5 & 1.0 & & & \\
\hline $07523-2626$ & WSI $54 \mathrm{AB}$ & HIP 38430 & 11.9353 & $\mathrm{y}$ & 3 & 229.2 & 0.7 & 0.0505 & 0.2 & 1.2 & & & \\
\hline $07523-2626$ & WSI $54 \mathrm{AC}$ & HIP 38430 & 11.9353 & $\mathrm{y}$ & 3 & 230.7 & 2.4 & 0.0964 & 6.6 & $1.6:$ & & & \\
\hline $08221-4059$ & HJ $4087 \mathrm{AB}$ & HIP 41006 & 11.9354 & $\mathrm{y}$ & 2 & 255.3 & 0.2 & 1.4580 & 0.7 & $0.4 *$ & 0.9 & 0.006 & USN2002 \\
\hline $08250-4246$ & CHR $226 \mathrm{Aa}, \mathrm{Ab}$ & HIP 41250 & 11.9354 & $\mathrm{y}$ & 2 & 97.9 & 5.1 & 0.0411 & 10.2 & 2.8 & & & \\
\hline $08250-4246$ & RST 4888 Aa,B & HIP 41250 & 11.9354 & $\mathrm{y}$ & 2 & 104.1 & 0.3 & 0.5372 & 0.1 & 1.1 & & & \\
\hline $08270-5242$ & В 1606 & HIP 41426 & 12.1019 & $\mathrm{y}$ & 2 & 290.8 & 0.1 & 0.0924 & 0.1 & 1.0 & -37.8 & -0.002 & ${ }^{*}$ Fin $1963 \mathrm{c}$ \\
\hline $08280-3507$ & FIN $314 \mathrm{Aa}, \mathrm{Ab}$ & HIP 41515 & 11.9354 & $\mathrm{y}$ & 2 & 45.6 & 0.1 & 0.1124 & 0.2 & 1.0 & -3.6 & -0.006 & Hrt2012a \\
\hline $08291-4756$ & FIN $315 \mathrm{Aa}, \mathrm{Ab}$ & HIP 41616 & 12.1019 & $\mathrm{y}$ & 2 & 203.2 & 0.4 & 0.1026 & 0.1 & 1.6 & 3.7 & 0.020 & Cve2010e \\
\hline $08327-5528$ & HDS $1221 \mathrm{Aa}, \mathrm{Ab}$ & HIP 41906 & 12.1019 & $\mathrm{y}$ & 2 & 45.4 & 0.9 & 0.0747 & 1.3 & 2.5 & & & \\
\hline $08345-3236$ & FIN 335 & HIP 42075 & 11.9354 & $\mathrm{y}$ & 2 & 203.5 & 0.1 & 0.1060 & 0.0 & 0.5 & -13.8 & 0.020 & *Sod1999 \\
\hline \multirow[t]{2}{*}{$08421-5245$} & В 1624 & HIP 42695 & 12.1019 & $\mathrm{y}$ & 2 & 224.2 & 0.2 & 0.2056 & 0.3 & 1.5 & -0.0 & 0.013 & Hrt2012a \\
\hline & & & 12.1019 & I & 2 & 223.9 & 0.9 & 0.2057 & 0.2 & 1.2 & -0.3 & 0.013 & Hrt2012a \\
\hline $08447-5443$ & I $10 \mathrm{AB}$ & HIP 42913 & 12.1019 & $\mathrm{y}$ & 2 & 279.8 & 1.1 & 0.3874 & 0.1 & 3.3 & 0.3 & -0.012 & Msn2011b \\
\hline $09125-4337$ & HJ $4188 \mathrm{AB}$ & HIP 45189 & 12.1839 & $\mathrm{y}$ & 2 & 280.6 & 0.9 & 2.8831 & 0.6 & $0.8 *$ & & & \\
\hline $09173-6841$ & FIN $363 \mathrm{AB}$ & HIP 45571 & 12.1020 & $\mathrm{y}$ & 2 & 189.9 & 0.0 & 0.1107 & 0.0 & 0.8 & -50.9 & 0.016 & *Sod1999 \\
\hline $09174-7454$ & I $12 \mathrm{AB}$ & HIP 45581 & 12.1020 & $\mathrm{y}$ & 2 & 260.5 & 0.3 & 0.3122 & 0.2 & 0.9 & & & \\
\hline \multirow[t]{2}{*}{$09191-4128$} & CHR 239 & HIP 45705 & 12.0285 & I & 2 & 344.9 & 0.8 & 0.1013 & 1.0 & 1.7 & & & \\
\hline & & & 12.0285 & $\mathrm{y}$ & 1 & 344.9 & 0.4 & 0.1050 & 0.4 & 2.4 & & & \\
\hline \multirow[t]{3}{*}{$09194-7739$} & $\mathrm{KOH} 83 \mathrm{Aa}, \mathrm{Ab}$ & HIP 45734 & 12.1020 & $\mathrm{y}$ & 3 & 147.2 & 0.6 & 0.1242 & 0.3 & 1.3 & & & \\
\hline & & & 12.1020 & I & 2 & 145.8 & 0.8 & 0.1244 & 0.1 & 0.6 & & & \\
\hline & & & 12.1020 & $\mathrm{R}$ & 2 & 146.5 & 0.5 & 0.1243 & 0.7 & 0.7 & & & \\
\hline $09243-3926$ & FIN 348 & HIP 46114 & 12.0285 & & 2 & 265.2 & 0.2 & 0.1601 & 0.0 & 0.4 & 0.2 & -0.003 & Msn2010c \\
\hline $09275-5806$ & CHR 240 & HIP 46388 & 12.0285 & $\mathrm{y}$ & 2 & 91.2 & 0.3 & 0.0385 & 0.3 & 0.3 & & & \\
\hline $09276-3500$ & B 2215 & HIP 46396 & 12.0285 & $\mathrm{y}$ & 2 & 37.8 & 0.5 & 0.0337 & 0.4 & 1.5 & & & \\
\hline & COP 1 & HIP 46651 & 12.0285 & $\mathrm{y}$ & 2 & 107.8 & 0.2 & 0.9185 & 0.2 & 1.5 & -2.4 & -0.083 & Msn2001c \\
\hline \multirow{2}{*}{$09415-1829$} & TOK $43 \mathrm{Aa}, \mathrm{Ab}$ & HIP 47537 & 12.0284 & $\mathrm{y}$ & 2 & 26.7 & 0.2 & 0.4309 & 0.5 & 2.0 & & & \\
\hline & & & 12.0284 & I & 2 & 26.7 & 0.1 & 0.4305 & 0.2 & 1.7 & & & \\
\hline
\end{tabular}


TABLE 1-Continued

\begin{tabular}{|c|c|c|c|c|c|c|c|c|c|c|c|c|c|}
\hline $\begin{array}{l}\text { WDS } \\
(2000)\end{array}$ & $\begin{array}{l}\text { Discoverer } \\
\text { Designation }\end{array}$ & $\begin{array}{l}\text { Other } \\
\text { name }\end{array}$ & $\begin{array}{l}\text { Epoch } \\
+2000\end{array}$ & Filt & $\mathrm{N}$ & $\begin{array}{c}\theta \\
(\operatorname{deg})\end{array}$ & $\begin{array}{l}\rho \sigma_{\theta} \\
\text { (mas) }\end{array}$ & $\begin{array}{l}\rho \\
\left(^{\prime \prime}\right)\end{array}$ & $\begin{array}{c}\sigma \rho \\
\text { (mas) }\end{array}$ & $\begin{array}{l}\Delta m \\
(\mathrm{mag})\end{array}$ & $\begin{array}{c}{[\mathrm{O}-\mathrm{C}]_{\theta}} \\
(\mathrm{deg})\end{array}$ & $\begin{array}{c}{[\mathrm{O}-\mathrm{C}]_{\rho}} \\
\left({ }^{\prime \prime}\right)\end{array}$ & $\begin{array}{l}\text { Reference } \\
\text { VB6 code }\end{array}$ \\
\hline $09416-3830$ & TOK 198 & HIP 47543 & 12.0285 & I & 2 & 46.8 & 5.3 & 0.4767 & 9.5 & 4.7 & & & \\
\hline $09442-2746$ & FIN 326 & HIP 47758 & 12.0284 & $\mathrm{y}$ & 2 & 21.7 & 0.0 & 0.1393 & 0.2 & 0.3 & 3.1 & -0.013 & Msn1999c \\
\hline $09527-7933$ & $\mathrm{KOH} 86$ & HD 86588 & 12.1020 & I & 2 & 287.5 & 0.8 & 0.2887 & 1.5 & 1.9 & & & \\
\hline $10093+2020$ & A 2145 & HIP 49747 & 12.1840 & $\mathrm{y}$ & 2 & 231.5 & 0.1 & 0.2076 & 0.3 & 0.8 & -10.9 & 0.032 & Msn2011e \\
\hline $10161-2837$ & TOK 199 & HIP 50288 & 12.0258 & $\mathrm{y}$ & 2 & 99.9 & 0.1 & 0.0353 & 0.1 & 0.7 & & & \\
\hline $10282-2548$ & B 199 AC & HIP 51255 & 12.0258 & $\mathrm{y}$ & 2 & 174.5 & 4.9 & 1.1578 & 4.4 & 3.7 & & & \\
\hline $10282-2548$ & FIN 308 AB & HIP 51255 & 12.0258 & $\mathrm{y}$ & 2 & 108.9 & 2.7 & 0.1363 & 1.4 & 0.7 & 0.4 & 0.002 & Hrt2012a \\
\hline $10311-2411$ & B 201 AB & HIP 51501 & 12.0258 & $\mathrm{y}$ & 2 & 68.1 & 1.0 & 1.9812 & 1.0 & $4.8 *$ & & & \\
\hline $10361-2641$ & BU 411 & HIP 51885 & 12.0259 & $\mathrm{y}$ & 2 & 306.1 & 0.3 & 1.3329 & 0.4 & $1.1 *$ & -0.6 & -0.055 & Sca2001b \\
\hline \multirow[t]{2}{*}{$10370-0850$} & A $556 \mathrm{Aa}, \mathrm{B}$ & HIP 51966 & 12.1840 & $\mathrm{y}$ & 2 & 196.8 & 0.3 & 0.8737 & 0.4 & 2.9 & -6.0 & 0.102 & Pop1978 \\
\hline & & & 12.1840 & I & 2 & 196.8 & 0.4 & 0.8738 & 0.2 & 2.2 & -6.0 & 0.102 & Pop1978 \\
\hline \multirow[t]{2}{*}{$10370-0850$} & TOK $44 \mathrm{Aa}, \mathrm{Ab}$ & HIP 51966 & 12.1840 & $\mathrm{y}$ & 2 & 58.0 & 1.4 & 0.1510 & 0.6 & 2.8 & & & \\
\hline & & & 12.1840 & I & 2 & 58.1 & 0.3 & 0.1509 & 0.1 & 2.3 & & & \\
\hline $10373-4814$ & SEE 119 & HIP 51986 & 12.1841 & $\mathrm{y}$ & 2 & 272.1 & 0.6 & 0.4361 & 0.8 & 1.7 & 2.4 & 0.006 & Doc2005f \\
\hline $10419-7811$ & HDS 1530 & HIP 52351 & 12.1020 & I & 2 & 152.2 & 0.5 & 0.1638 & 0.3 & 0.8 & & & \\
\hline \multirow{3}{*}{$10465-6416$} & FIN $364 \mathrm{AB}$ & HIP 52701 & 12.1020 & $\mathrm{y}$ & 2 & 151.7 & 0.9 & 0.0737 & 1.6 & 0.7 & 1.5 & 0.012 & Hrt2012a \\
\hline & & & 12.1840 & $\mathrm{y}$ & 3 & 150.6 & 2.2 & 0.0759 & 1.4 & 0.8 & 1.7 & 0.013 & Hrt2012a \\
\hline & & & 12.1840 & I & 2 & 152.2 & 0.8 & 0.0761 & 0.6 & 0.8 & 3.3 & 0.013 & Hrt2012a \\
\hline \multirow[t]{3}{*}{$10465-6416$} & TOK $45 \mathrm{AC}$ & HIP 52701 & 12.1020 & $\mathrm{y}$ & 2 & 13.9 & 0.5 & 0.7072 & 1.0 & 4.3 & & & \\
\hline & & & 12.1840 & $\mathrm{y}$ & 3 & 13.6 & 1.1 & 0.7086 & 4.9 & 4.5 & & & \\
\hline & & & 12.1840 & I & 2 & 13.5 & 1.2 & 0.7082 & 0.4 & 3.8 & & & \\
\hline $11009-4030$ & FIN 365 & HIP 53840 & 12.0258 & $\mathrm{y}$ & 2 & 112.9 & 0.2 & 0.1486 & 0.1 & 0.3 & -7.4 & 0.030 & ${ }^{*} \mathrm{Hrt} 2012 \mathrm{a}$ \\
\hline $11014-1204$ & HDS 1572 & HIP 53879 & 12.1023 & $\mathrm{y}$ & 2 & 140.1 & 0.2 & 0.1167 & 0.2 & 1.8 & & & \\
\hline $11056-1105$ & new & HIP 54214 & 12.1024 & I & 2 & 60.2 & 2.6 & 0.5923 & 5.6 & 5.4 & & & \\
\hline $11102-1122$ & HDS 1590 & HIP 54580 & 12.1024 & $\mathrm{y}$ & 2 & 324.9 & 0.1 & 0.1123 & 0.5 & 0.4 & 0.3 & 0.002 & Hrt2012a \\
\hline $11190+1416$ & STF 1527 & HIP 55254 & 12.1840 & $\mathrm{y}$ & 2 & 208.5 & 0.5 & 0.3186 & 0.1 & 1.2 & -60.1 & 0.158 & *Pru2009 \\
\hline $11210-5429$ & I 879 & HIP 55425 & 12.1842 & $\mathrm{y}$ & 2 & 253.9 & 0.3 & 0.1163 & 0.0 & 1.5 & -11.9 & 0.047 & *Msn1999a \\
\hline $11318-2047$ & new & HIP 56245 & 12.1023 & I & 2 & 65.2 & 2.7 & 1.0501 & 2.3 & $4.9 *$ & & & \\
\hline $11342+1101$ & HDS 1642 & HIP 56429 & 12.1840 & $\mathrm{y}$ & 2 & 245.6 & 0.4 & 1.1225 & 0.4 & $2.6 *$ & & & \\
\hline \multirow{2}{*}{$11514+1148$} & HDS 1672 & HIP 57821 & 12.1840 & $\mathrm{y}$ & 2 & 87.5 & 0.7 & 0.1882 & 0.7 & 3.6 & & & \\
\hline & & & 12.1840 & I & 2 & 87.1 & 4.5 & 0.1871 & 3.2 & 3.2 & & & \\
\hline $11525-1408$ & HDS 1676 & HIP 57894 & 12.1023 & $\mathrm{y}$ & 2 & 126.7 & 0.2 & 0.1902 & 0.2 & 1.4 & & & \\
\hline $12342-1812$ & LV 5 & HIP 61345 & 12.1024 & $\mathrm{y}$ & 3 & 311.9 & 0.5 & 0.9581 & 0.2 & 2.3 & & & \\
\hline $12357-1650$ & FIN $368 \mathrm{Aa}, \mathrm{Ab}$ & HIP 61463 & 12.1024 & $\mathrm{y}$ & 2 & 107.1 & 0.2 & 0.1307 & 0.2 & 1.7 & 0.7 & 0.005 & This work \\
\hline \multirow[t]{2}{*}{$12444+2200$} & HDS 1783 & HIP 62162 & 12.1843 & $\mathrm{y}$ & 1 & 278.2 & 1.9 & 0.1451 & 1.9 & 3.5 & & & \\
\hline & & & 12.1843 & I & 2 & 277.1 & 5.2 & 0.1459 & 1.0 & 2.7 & & & \\
\hline $12485-1543$ & WSI $9109 \mathrm{Aa}, \mathrm{Ab}$ & HIP 62505 & 12.1024 & & 3 & 288.5 & 0.7 & 0.0806 & 2.3 & 1.3 & & & \\
\hline $12533+2115$ & STF $1687 \mathrm{AB}$ & HIP 62886 & 12.1844 & $\mathrm{y}$ & 2 & 193.6 & 0.7 & 1.1651 & 1.3 & 3.0 & -4.1 & 0.133 & Hei1997 \\
\hline $13064+2109$ & $\mathrm{COU} 11 \mathrm{AB}$ & HIP 63948 & 12.1843 & $\mathrm{y}$ & 3 & 315.6 & 1.5 & 1.7614 & 1.5 & $4.1 *$ & & & \\
\hline & CHR $247 \mathrm{Aa}, \mathrm{Ab}$ & HIP 64094 & 12.1844 & $\mathrm{y}$ & 2 & 305.8 & 0.7 & 0.0289 & 0.8 & 0.7 & & & \\
\hline \multirow[t]{2}{*}{$13106-3128$} & RST 1706 & HIP 64292 & 12.1843 & $\mathrm{y}$ & 2 & 124.4 & 0.5 & 0.1744 & 0.5 & 2.3 & -0.5 & 0.001 & This work \\
\hline & & & 12.1843 & I & 2 & 124.4 & 0.2 & 0.1744 & 0.3 & 1.8 & -0.5 & 0.001 & This work \\
\hline $13126-6034$ & WSI $75 \mathrm{Aa}, \mathrm{Ab}$ & HD 114566 & 12.1844 & $\mathrm{y}$ & 2 & 84.0 & 1.1 & 0.0905 & 1.2 & 3.0 & & & \\
\hline $13129-5949$ & HDS $1850 \mathrm{Aa}, \mathrm{Ab}$ & HIP 64478 & 12.1024 & $\mathrm{y}$ & 2 & 99.3 & 1.9 & 0.3167 & 1.8 & 3.6 & 0.5 & -0.002 & This work \\
\hline
\end{tabular}


TABLE 1-Continued

\begin{tabular}{|c|c|c|c|c|c|c|c|c|c|c|c|c|c|}
\hline $\begin{array}{c}\text { WDS } \\
(2000)\end{array}$ & $\begin{array}{l}\text { Discoverer } \\
\text { Designation }\end{array}$ & $\begin{array}{l}\text { Other } \\
\text { name }\end{array}$ & $\begin{array}{l}\text { Epoch } \\
+2000\end{array}$ & Filt & $\mathrm{N}$ & $\begin{array}{c}\theta \\
(\mathrm{deg})\end{array}$ & $\begin{array}{l}\rho \sigma_{\theta} \\
\text { (mas) }\end{array}$ & $\begin{array}{l}\rho \\
\left(^{\prime \prime}\right)\end{array}$ & $\begin{array}{l}\sigma \rho \\
\text { (mas) }\end{array}$ & $\begin{array}{l}\Delta m \\
\text { (mag) }\end{array}$ & $\begin{array}{c}{[\mathrm{O}-\mathrm{C}]_{\theta}} \\
(\mathrm{deg})\end{array}$ & $\begin{array}{c}{[\mathrm{O}-\mathrm{C}]_{\rho}} \\
\left({ }^{\prime \prime}\right)\end{array}$ & $\begin{array}{l}\text { Reference } \\
\text { VB6 code }\end{array}$ \\
\hline $13137-6248$ & HDS 1852 & HIP 64537 & 12.1844 & I & 2 & 131.9 & 0.4 & 0.1771 & 0.4 & 0.4 & & & \\
\hline $13138-6335$ & WSI 57 & HD 114737 & 12.1844 & $\mathrm{y}$ & 2 & 54.0 & 0.7 & 0.1932 & 0.7 & 2.3 & & & \\
\hline $13147-6335$ & MLO 3 Aa,B & HIP 64624 & 12.1844 & $\mathrm{y}$ & 3 & 38.4 & 2.8 & 1.6923 & 2.6 & 3.5 & & & \\
\hline $13147-6335$ & WSI $58 \mathrm{Aa}, \mathrm{Ab}$ & HIP 64624 & 12.1844 & $\mathrm{y}$ & 3 & 279.9 & 1.9 & 0.2460 & 0.7 & 2.2 & & & \\
\hline $13169-3436$ & I 1567 & HIP 64804 & 12.1843 & $\mathrm{y}$ & 2 & 135.7 & 0.1 & 0.2811 & 0.1 & 1.2 & -3.5 & 0.058 & ${ }^{*}$ Hei1986a \\
\hline $13175-0041$ & FIN 350 & HIP 64838 & 12.1843 & $\mathrm{y}$ & 2 & 8.0 & 0.1 & 0.1214 & 0.2 & 0.6 & -0.5 & -0.001 & Hor $2011 b$ \\
\hline $13275+2116$ & TOK 46 & HD 117078 & 12.1843 & I & 3 & 2.9 & 0.7 & 0.1263 & 1.4 & 1.1 & & & \\
\hline $13317-0219$ & HDS 1895 & HIP 65982 & 12.1843 & $\mathrm{y}$ & 2 & 128.6 & 0.7 & 0.1496 & 0.5 & 1.4 & 0.5 & 0.004 & Hrt2012a \\
\hline $13320-6519$ & FIN 369 & HIP 66005 & 12.1844 & $\mathrm{y}$ & 2 & 317.5 & 0.1 & 0.0737 & 0.2 & 0.7 & -0.5 & 0.001 & Doc2011c \\
\hline \multirow[t]{2}{*}{$13513-2423$} & WSI 77 & HIP 67620 & 12.1843 & $\mathrm{y}$ & 2 & 52.3 & 0.2 & 0.0261 & 0.5 & 1.2 & -4.3 & -0.014 & This work \\
\hline & & & 12.1843 & $\mathrm{H} \alpha$ & 1 & 54.3 & 0.3 & 0.0392 & 0.3 & 1.7 & -2.3 & -0.001 & This work \\
\hline $13539-1910$ & HU 898 & HIP 67859 & 12.1843 & $\mathrm{y}$ & 2 & 295.9 & 0.2 & 0.3442 & 0.2 & 0.6 & -0.5 & 0.001 & Doc2012a \\
\hline $14150-6142$ & $\mathrm{COO} 167 \mathrm{~A}, \mathrm{Ba}$ & HIP 69628 & 12.1844 & I & 2 & 157.0 & 7.2 & 2.7737 & 3.9 & 2.6 & & & \\
\hline $14150-6142$ & WSI $59 \mathrm{Ba}, \mathrm{Bb}$ & HIP 69628 & 12.1844 & I & 2 & 244.0 & 5.5 & 0.2133 & 1.4 & 2.2 & & & \\
\hline \multirow[t]{2}{*}{$14152-6739$} & DON 652 & HIP 69643 & 12.1844 & I & 2 & 274.6 & 0.7 & 0.4128 & 1.5 & 2.7 & & & \\
\hline & & & 12.1844 & $\mathrm{y}$ & 1 & 274.8 & 1.7 & 0.4131 & 1.7 & 3.6 & & & \\
\hline $15088-4517$ & SEE $219 \mathrm{AB}$ & HIP 74117 & 12.1845 & $\mathrm{y}$ & 2 & 91.4 & 0.0 & 0.1082 & 0.0 & 0.8 & 27.0 & -0.010 & *Doc2007d \\
\hline \multirow[t]{2}{*}{$15143-4242$} & B $1273 \mathrm{Aa}, \mathrm{B}$ & HD 134976 & 12.1845 & y & 1 & $\begin{array}{r}131.9 \\
131.9\end{array}$ & 0.0 & 0.5647 & 0.0 & 1.7 & & & \\
\hline & & & 12.1845 & I & 2 & 131.9 & 0.2 & 0.5624 & 0.2 & 0.9 & & & \\
\hline \multirow[t]{2}{*}{$15143-4242$} & WSI $82 \mathrm{Aa}, \mathrm{Ab}$ & HD 134976 & 12.1845 & $\mathrm{y}$ & 1 & 41.7 & 0.0 & 0.0504 & 0.0 & 2.2 & & & \\
\hline & & & 12.1845 & I & 2 & 45.3 & 2.1 & 0.0507 & 2.1 & 1.4 & & & \\
\hline $15234-5919$ & HJ 4757 & HIP 75323 & 12.1844 & $\mathrm{y}$ & 2 & 0.8 & 0.1 & 0.8239 & 0.8 & 1.0 & 1.7 & 0.001 & Hrt2010a \\
\hline $15332-2429$ & SEE $238 \mathrm{Ba}, \mathrm{Bb}$ & HIP 76143 & 12.1845 & $\mathrm{y}$ & 2 & 122.7 & 0.2 & 0.2558 & 0.2 & 0.5 & -1.5 & -0.024 & Hei1988d \\
\hline $15339-1700$ & HDS 2185 & HIP 76203 & 12.1845 & $\mathrm{y}$ & 2 & 309.6 & 0.3 & 0.3368 & 0.3 & 1.8 & 0.0 & 0.002 & This work \\
\hline $15348-2808$ & RST $1847 \mathrm{Aa}, \mathrm{B}$ & HIP 76275 & 12.1845 & I & 2 & 335.0 & 2.8 & 0.9433 & 1.6 & 2.0 & & & \\
\hline $15348-2808$ & TOK $49 \mathrm{Aa}, \mathrm{Ab}$ & HIP 76275 & 12.1845 & I & 2 & 222.0 & 0.8 & 0.1212 & 0.2 & 2.1 & & & \\
\hline $15351-4110$ & HJ 4786 & HIP 76297 & 12.1845 & $\mathrm{y}$ & 2 & 275.7 & 0.1 & 0.8242 & 0.1 & 0.6 & -1.0 & -0.002 & Hei1990c \\
\hline $15355-4751$ & HDS 2191 & HIP 76328 & 12.1845 & I & 2 & 201.4 & $\begin{array}{l}0.1 \\
0.4\end{array}$ & 0.2298 & $\begin{array}{l}0.1 \\
0.5\end{array}$ & 0.8 & & & \\
\hline \multirow[t]{2}{*}{$15428-1601$} & $\mathrm{BU} 35 \mathrm{AB}$ & HIP 76954 & 12.1845 & $\mathrm{y}$ & 2 & 109.2 & 0.4 & 1.6935 & 0.1 & $1.3 *$ & & & \\
\hline & & & 12.3539 & $\mathrm{y}$ & 2 & 109.4 & 0.2 & 1.6920 & 1.1 & $1.5 *$ & & & \\
\hline \multirow[t]{2}{*}{$15462-2804$} & $\mathrm{BU} 620 \mathrm{AB}$ & HIP 77235 & 12.1845 & I & 2 & 173.4 & 0.1 & 0.6324 & 0.1 & 0.5 & & & \\
\hline & & & 12.1845 & $\mathrm{y}$ & 1 & 173.5 & 0.0 & 0.6323 & 0.0 & 0.8 & & & \\
\hline $15471-5107$ & B $1790 \mathrm{~A}, \mathrm{Ba}$ & HD 140662 & 12.1844 & I & 2 & 84.0 & 3.4 & 0.4257 & 1.6 & 1.0 & & & \\
\hline $15471-5107$ & WSI $78 \mathrm{Ba}, \mathrm{Bb}$ & HD 140662 & 12.1844 & I & 2 & 225.5 & 0.2 & 0.0654 & 0.4 & 0.2 & & & \\
\hline $16048-4044$ & I 1284 & HIP 78765 & 12.3539 & $\mathrm{y}$ & 2 & 234.9 & 0.1 & 0.1224 & 0.1 & 0.7 & & & \\
\hline \multirow[t]{2}{*}{$16057-3252$} & $\mathrm{SEE} 264 \mathrm{~A}, \mathrm{Ba}$ & HIP 78842 & 12.3539 & $\mathrm{y}$ & 2 & 15.0 & 0.4 & 0.8140 & 0.2 & 1.6 & 1.5 & 0.028 & Doc2009f \\
\hline & & & 12.3539 & I & 1 & 15.0 & 0.0 & 0.8129 & 0.0 & 1.3 & 1.5 & 0.027 & Doc2009f \\
\hline \multirow[t]{2}{*}{$16057-3252$} & WSI $84 \mathrm{Ba}, \mathrm{Bb}$ & HIP 78842 & 12.3539 & $\mathrm{y}$ & 2 & 163.2 & 0.6 & 0.0979 & 0.4 & 0.0 & & & \\
\hline & & & 12.3539 & I & 1 & 162.6 & 0.0 & 0.0973 & 0.0 & 0.0 & & & \\
\hline $16120-1928$ & BU 120 Aa.B & HIP 79374 & 12.3540 & $\mathrm{y}$ & 3 & 1.4 & 0.3 & 1.3586 & 0.7 & $\begin{array}{l}0.0 \\
1.2\end{array}$ & & & \\
\hline & $\mathrm{CHR} 146 \mathrm{Aa}, \mathrm{Ab}$ & HIP 79374 & 12.3540 & $\mathrm{y}$ & 3 & 345.8 & 0.9 & 0.0758 & 3.5 & 2.4 & & & \\
\hline \multirow[t]{2}{*}{$16253-4909$} & COO $197 \mathrm{Aa}, \mathrm{B}$ & HIP 80448 & 12.1846 & y & 2 & 95.6 & 5.7 & 2.3138 & 1.4 & 1.5 & 0.8 & 0.029 & $\mathrm{Alz} 2009 \mathrm{~b}$ \\
\hline & & & 12.1846 & $\mathrm{I}$ & 2 & 95.7 & 3.5 & 2.3083 & 0.1 & 0.9 & 0.9 & 0.023 & Alz2009b \\
\hline $16253-4909$ & TOK $50 \mathrm{Aa}, \mathrm{Ab}$ & HIP 80448 & 12.1846 & $\mathrm{y}$ & 2 & 184.8 & 2.9 & 0.2188 & 11.6 & 3.5 & & & \\
\hline
\end{tabular}


TABLE 1-Continued

\begin{tabular}{|c|c|c|c|c|c|c|c|c|c|c|c|c|c|}
\hline $\begin{array}{l}\text { WDS } \\
(2000)\end{array}$ & $\begin{array}{l}\text { Discoverer } \\
\text { Designation }\end{array}$ & $\begin{array}{l}\text { Other } \\
\text { name }\end{array}$ & $\begin{array}{l}\text { Epoch } \\
+2000\end{array}$ & Filt & $\mathrm{N}$ & $\begin{array}{c}\theta \\
(\operatorname{deg})\end{array}$ & $\begin{array}{l}\rho \sigma_{\theta} \\
\text { (mas) }\end{array}$ & $\begin{array}{l}\rho \\
\left({ }^{\prime \prime}\right)\end{array}$ & $\begin{array}{c}\sigma \rho \\
\text { (mas) }\end{array}$ & $\begin{array}{l}\Delta m \\
(\mathrm{mag})\end{array}$ & $\begin{array}{c}{[\mathrm{O}-\mathrm{C}]_{\theta}} \\
(\mathrm{deg})\end{array}$ & $\begin{array}{c}{[\mathrm{O}-\mathrm{C}]_{\rho}} \\
\left({ }^{\prime \prime}\right)\end{array}$ & $\begin{array}{l}\text { Reference } \\
\text { VB6 code }\end{array}$ \\
\hline \multirow{3}{*}{$16385-5728$} & & & 12.1846 & I & 2 & 184.6 & 0.5 & 0.2219 & 3.1 & 2.9 & & & \\
\hline & RST 869 Aa,B & HIP 81478 & 12.1846 & I & 2 & 45.0 & 0.1 & 0.8351 & 0.9 & 4.1 & & & \\
\hline & & & 12.1846 & $\mathrm{y}$ & 2 & 44.8 & 3.8 & 0.8426 & 6.2 & 3.4 & & & \\
\hline \multirow[t]{2}{*}{$16385-5728$} & TOK $51 \mathrm{Aa}, \mathrm{Ab}$ & HIP 81478 & 12.1846 & I & 2 & 59.8 & 2.7 & 0.3327 & 1.3 & 2.7 & & & \\
\hline & & & 12.1846 & $\mathrm{y}$ & 2 & 59.1 & 4.2 & 0.3311 & 3.8 & 3.8 & & & \\
\hline $16391-3713$ & FIN $340 \mathrm{AB}$ & HIP 81523 & 12.3539 & $\mathrm{y}$ & 2 & 189.8 & 0.0 & 0.0452 & 0.1 & 0.0 & 15.5 & -0.008 & Hrt2012a \\
\hline $16534-2025$ & WSI 86 & HIP 82621 & 12.3540 & I & 2 & 109.9 & 3.1 & 0.1851 & 2.9 & 2.9 & & & \\
\hline $17031-5314$ & HDS $2412 \mathrm{Aa}, \mathrm{Ab}$ & HIP 83431 & 12.3540 & $\mathrm{y}$ & 2 & 188.1 & 0.3 & 0.6209 & 0.2 & 3.3 & & & \\
\hline \multirow[t]{2}{*}{$17066+0039$} & $\mathrm{BU} 823 \mathrm{~A}, \mathrm{Ba}$ & HIP 83716 & 12.3541 & $\mathrm{y}$ & 2 & 166.9 & 0.6 & 1.0027 & 2.9 & 2.0 & -1.8 & -0.007 & Hrt2000c \\
\hline & & & 12.3541 & I & 2 & 167.1 & 4.1 & 1.0058 & 9.6 & 1.5 & -1.6 & -0.004 & Hrt2000c \\
\hline \multirow[t]{2}{*}{$17066+0039$} & TOK $52 \mathrm{Ba}, \mathrm{Bb}$ & HIP 83716 & 12.3541 & $\mathrm{y}$ & 2 & 121.5 & 4.0 & 0.0437 & 0.4 & 0.1 & & & \\
\hline & & & 12.3541 & I & 2 & 110.7 & 4.4 & 0.0471 & 10.0 & 0.2 & & & \\
\hline $17157-0949$ & A $2592 \mathrm{~A}, \mathrm{Ba}$ & HIP 84430 & 12.3541 & $\mathrm{y}$ & 2 & 122.6 & 0.9 & 0.1754 & 1.6 & 1.4 & -23.6 & 0.002 & Hei1996c \\
\hline $17157-0949$ & TOK $53 \mathrm{Ba}, \mathrm{Bb}$ & HIP 84430 & 12.3541 & $\mathrm{y}$ & 2 & 215.9 & 1.8 & 0.0380 & 2.1 & 0.3 & & & \\
\hline $17195-5004$ & FIN 356 & HIP 84759 & 12.3540 & $\mathrm{y}$ & 1 & 70.7 & 0.0 & 0.0617 & 0.0 & 0.2 & & & \\
\hline $17248-5913$ & I $385 \mathrm{AB}$ & HIP 85216 & 12.3540 & $\mathrm{y}$ & 2 & 120.1 & 0.6 & 0.3984 & 1.4 & 0.5 & & & \\
\hline $17248-5913$ & I $385 \mathrm{AD}$ & HIP 85216 & 12.3540 & $\mathrm{y}$ & 2 & 271.7 & 1.6 & 0.2690 & 0.2 & 0.5 & & & \\
\hline $17297-4947$ & I 1323 & HIP 85610 & 12.3540 & $\mathrm{y}$ & 2 & 105.7 & 0.2 & 0.2598 & 0.1 & 0.5 & & & \\
\hline $17305-1006$ & RST 3978 & HIP 85675 & 12.3541 & $\mathrm{y}$ & 2 & 72.8 & 0.9 & 0.2048 & 0.6 & 2.3 & & & \\
\hline $17390+0240$ & WSI 88 & HIP 86374 & 12.3541 & $\mathrm{y}$ & 2 & 6.7 & 0.6 & 0.1884 & 1.1 & 2.9 & & & \\
\hline $17415-5348$ & HDS 2502 & HIP 86569 & 12.3540 & $\mathrm{y}$ & 2 & 166.4 & 0.7 & 0.1821 & 0.2 & 0.6 & & & \\
\hline $17535-0355$ & TOK 54 & V2610 Oph & 12.3541 & $\mathrm{y}$ & 2 & 314.5 & 0.6 & 0.1149 & 0.2 & 0.8 & & & \\
\hline & A 2189 & HIP 87811 & 12.3541 & $\mathrm{y}$ & 2 & 275.2 & 0.4 & 0.1048 & 0.3 & 1.0 & -6.0 & 0.006 & Doc2008a \\
\hline \multirow[t]{2}{*}{$17575-5740$} & HJ $4992 \mathrm{~A}, \mathrm{Ba}$ & HIP 87914 & 12.3540 & $\mathrm{y}$ & 2 & 40.8 & 4.2 & 2.5736 & 3.9 & 2.0 & & & \\
\hline & & & 12.3540 & I & 2 & 40.8 & 3.3 & 2.5732 & 3.4 & 1.3 & & & \\
\hline \multirow[t]{2}{*}{$17575-5740$} & TOK $55 \mathrm{Ba}, \mathrm{Bb}$ & HIP 87914 & 12.3540 & $\mathrm{y}$ & 2 & 160.1 & 1.4 & 0.1485 & 5.8 & 0.4 & & & \\
\hline & & & 12.3540 & I & 2 & 161.3 & 4.5 & 0.1392 & 6.2 & 0.4 & & & \\
\hline
\end{tabular}


TABLE 2

UnResolved Stars

\begin{tabular}{|c|c|c|c|c|c|c|c|}
\hline \multirow[t]{2}{*}{ WDS (2000) } & \multirow{2}{*}{$\begin{array}{c}\text { Discoverer } \\
\text { Designation } \\
\text { or other name }\end{array}$} & \multirow[t]{2}{*}{ HIP } & \multirow{2}{*}{$\begin{array}{l}\text { Epoch } \\
+2000\end{array}$} & \multirow[t]{2}{*}{ Filter } & \multirow[t]{2}{*}{$\mathrm{N}$} & \multicolumn{2}{|c|}{$5 \sigma$ Detection Limit } \\
\hline & & & & & & $\begin{array}{c}\Delta m\left(0^{\prime \prime} .^{\prime} 15\right) \\
(\mathrm{mag})\end{array}$ & $\begin{array}{c}\Delta m\left(1^{\prime \prime}\right) \\
(\mathrm{mag})\end{array}$ \\
\hline \multirow[t]{3}{*}{$05074+1839$} & \multirow[t]{3}{*}{ A 3010} & \multirow[t]{3}{*}{ HIP 23835} & 12.0253 & $\mathrm{H} \alpha$ & 1 & 3.82 & 4.51 \\
\hline & & & 12.0253 & $\mathrm{y}$ & 1 & 4.91 & 6.20 \\
\hline & & & 12.0253 & $\mathrm{~V}$ & 1 & 4.62 & 5.56 \\
\hline $07383-2522$ & B 731 & HIP 37173 & 11.9353 & $\mathrm{y}$ & 2 & 5.01 & 6.85 \\
\hline $07522-4035$ & TOK 195 & HIP 38414 & 11.9354 & $\mathrm{y}$ & 2 & 4.83 & 6.95 \\
\hline $08095-4720$ & $\mathrm{TOK} 2 \mathrm{Aa}, \mathrm{Ab}$ & HIP 39953 & 12.1019 & $\mathrm{y}$ & 4 & 5.17 & 6.98 \\
\hline $09024-6624$ & TOK 197 & HIP 44382 & 12.1020 & y & 2 & 4.93 & 6.49 \\
\hline $09380-5924$ & HIP 47263 & HIP 47263 & 12.0285 & $\mathrm{y}$ & 2 & 4.69 & 5.17 \\
\hline $09416-3830$ & TOK 198 & HIP 47543 & 12.0285 & $\mathrm{y}$ & 1 & 4.57 & 5.08 \\
\hline $11056-1105$ & new & HIP 54214 & 12.1024 & $\mathrm{y}$ & 2 & 4.98 & 6.66 \\
\hline \multirow[t]{2}{*}{$11126-4906$} & \multirow[t]{2}{*}{ HIP 54746} & \multirow[t]{2}{*}{ HIP 54746} & 12.1842 & $\mathrm{y}$ & 2 & 4.79 & 6.70 \\
\hline & & & 12.1842 & I & 2 & 4.04 & 5.72 \\
\hline \multirow[t]{2}{*}{$11154-5249$} & \multirow[t]{2}{*}{ HIP 54977} & \multirow[t]{2}{*}{ HIP 54977} & 12.1842 & $\mathrm{y}$ & 2 & 4.02 & 4.75 \\
\hline & & & 12.1842 & $\mathrm{I}$ & 2 & 3.09 & 4.60 \\
\hline $11234-1847$ & HIP 55598 & HIP 55598 & 12.1023 & I & 2 & 3.85 & 5.56 \\
\hline $11317+1422$ & WSI $9107 \mathrm{Aa}, \mathrm{Ab}$ & HIP 56242 & 12.1840 & $\mathrm{y}$ & 2 & 5.00 & 6.15 \\
\hline $13069-3407$ & HIP 64006 & HIP 64006 & 12.1842 & I & 2 & 3.97 & 5.73 \\
\hline \multirow[t]{2}{*}{$13143-5906$} & \multirow[t]{2}{*}{ HIP 64583} & \multirow[t]{2}{*}{ HIP 64583} & 12.1024 & $\mathrm{y}$ & 2 & 5.22 & 6.67 \\
\hline & & & 12.1024 & I & 2 & 3.79 & 6.12 \\
\hline $13526-1843$ & WSI 78 & HIP 67744 & 12.1843 & y & 2 & 4.74 & 5.66 \\
\hline \multirow{2}{*}{$15168-1302$} & \multirow[t]{2}{*}{ CHR 44} & \multirow[t]{2}{*}{ HIP 74765} & 12.1845 & y & 2 & 4.64 & 5.54 \\
\hline & & & 12.1845 & I & 1 & 3.87 & 5.35 \\
\hline \multirow[t]{2}{*}{$15384-1955$} & \multirow[t]{2}{*}{ CHR 48} & \multirow[t]{2}{*}{ HIP 76582} & 12.3539 & $\mathrm{y}$ & 2 & 4.80 & 6.60 \\
\hline & & & 12.3539 & $\mathrm{I}$ & 2 & 3.97 & 5.86 \\
\hline $15355-1447$ & WRH $20 \mathrm{Aa}, \mathrm{Ab}$ & HIP 76333 & 12.1845 & $\mathrm{y}$ & 2 & 5.05 & 7.03 \\
\hline $15453-5841$ & FIN $234 \mathrm{AB}$ & HIP 77160 & 12.1844 & $\mathrm{y}$ & 2 & 4.19 & 4.76 \\
\hline $15467-4314$ & I 1276 & HIP 77282 & 12.1845 & $\mathrm{y}$ & 1 & 4.47 & 5.22 \\
\hline & & & 12.1845 & I & 1 & 3.57 & 5.14 \\
\hline $16057-3252$ & SEE $264 C$ & HIP 78842 & 12.3539 & $\mathrm{y}$ & 1 & 3.31 & 3.63 \\
\hline & & & 12.3539 & I & 1 & 3.99 & 5.22 \\
\hline $16245-3734$ & B $868 \mathrm{AB}$ & HIP 80390 & 12.3539 & $\mathrm{y}$ & 2 & 5.02 & 7.10 \\
\hline $16534-2025$ & WSI 86 & HIP 82621 & 12.3540 & $\mathrm{y}$ & 2 & 5.11 & 7.25 \\
\hline $16542-4150$ & CHR 252Aa,Ab & HIP 82691 & 12.3539 & $\mathrm{I}$ & 1 & 3.65 & 5.28 \\
\hline $16544-3806$ & HDS2392 & HIP 82709 & 12.3539 & $\mathrm{I}$ & 2 & 3.87 & 4.92 \\
\hline $16571-1749$ & HIP 82956 & HIP 82956 & 12.3540 & $\mathrm{y}$ & 2 & 4.78 & 6.30 \\
\hline & & & 12.3540 & I & 2 & 4.06 & 5.89 \\
\hline $17213-5107$ & HIP 84924 & HIP 84924 & 12.3540 & y & 2 & 4.90 & 6.29 \\
\hline & & & 12.3540 & I & 2 & 3.67 & 5.67 \\
\hline
\end{tabular}


TABLE 3

New and Revised Orbital Elements

\begin{tabular}{|c|c|c|c|c|c|c|c|c|c|c|}
\hline $\begin{array}{c}\text { WDS } \\
\text { (Figure) }\end{array}$ & $\begin{array}{c}\text { Discoverer } \\
\text { HIP }\end{array}$ & $\begin{array}{c}\mathrm{P} \\
(\mathrm{yr})\end{array}$ & $\begin{array}{l}\mathrm{a} \\
\left({ }^{\prime \prime}\right)\end{array}$ & $\begin{array}{l}\mathrm{i} \\
(\mathrm{o})\end{array}$ & $\begin{array}{l}\Omega \\
(0)\end{array}$ & $\begin{array}{l}\mathrm{T}_{o} \\
(\mathrm{yr})\end{array}$ & $\mathrm{e}$ & $\begin{array}{l}\omega \\
(\circ)\end{array}$ & $\mathrm{Gr}$ & $\begin{array}{l}\text { Published Orbit } \\
\text { VB6 Reference }\end{array}$ \\
\hline $\begin{array}{c}06359-3605 \\
(1 \mathrm{a})\end{array}$ & $\begin{array}{l}\mathrm{RST} 4816 \mathrm{Ba}, \mathrm{Bb} \\
31547\end{array}$ & $\begin{array}{l}14.00 \\
\pm 0.04\end{array}$ & $\begin{array}{r}0.1824 \\
\pm 0.0076\end{array}$ & $\begin{array}{r}111.6 \\
\pm 1.5\end{array}$ & $\begin{array}{r}289.7 \\
\pm 0.9\end{array}$ & $\begin{array}{r}1990.036 \\
\pm 0.061\end{array}$ & $\begin{array}{r}0.577 \\
\pm 0.031\end{array}$ & $\begin{array}{r}296.1 \\
\pm 1.6\end{array}$ & 3 & Cve2008b \\
\hline $\begin{array}{c}07518-1354 \\
(1 \mathrm{~b})\end{array}$ & $\begin{array}{l}\text { BU } 101 \\
38382\end{array}$ & $\begin{array}{l}23.330 \\
\pm 0.010\end{array}$ & $\begin{array}{r}0.6179 \\
\pm 0.0024\end{array}$ & $\begin{array}{r}80.82 \\
\pm 0.06\end{array}$ & $\begin{array}{r}282.65 \\
\pm 0.09\end{array}$ & $\begin{array}{r}1985.923 \\
\pm 0.011\end{array}$ & $\begin{array}{r}0.7647 \\
\pm 0.0021\end{array}$ & $\begin{array}{l}253.64 \\
\pm 0.12\end{array}$ & 1 & $\mathrm{Pbx} 2000 \mathrm{~b}$ \\
\hline $\begin{array}{c}08270-5242 \\
(1 c)\end{array}$ & $\begin{array}{l}\text { В } 1606 \\
41426\end{array}$ & $\begin{array}{l}14.778 \\
\pm 0.077\end{array}$ & $\begin{array}{r}0.1496 \\
\pm 0.0062\end{array}$ & $\begin{array}{r}59.5 \\
\pm 2.5\end{array}$ & $\begin{array}{r}96.5 \\
\pm 2.5\end{array}$ & $\begin{array}{r}1952.54 \\
\pm 0.46\end{array}$ & $\begin{array}{r}0.337 \\
\pm 0.023\end{array}$ & $\begin{array}{l}183.8 \\
\pm 8.1\end{array}$ & 2 & Fin1963c \\
\hline $\begin{array}{c}08345-3236 \\
(1 \mathrm{~d})\end{array}$ & $\begin{array}{l}\text { FIN } 335 \\
42075\end{array}$ & $\begin{array}{l}17.35 \\
\pm 0.05\end{array}$ & $\begin{array}{r}0.1445 \\
\pm 0.0056\end{array}$ & $\begin{array}{r}37.5 \\
\pm 4.5\end{array}$ & $\begin{array}{r}100.1 \\
\pm 3.5\end{array}$ & $\begin{array}{r}1997.00 \\
\pm 0.16\end{array}$ & $\begin{array}{r}0.5564 \\
\pm 0.0099\end{array}$ & $\begin{array}{l}217.2 \\
\pm 4.2\end{array}$ & 3 & Sod1999 \\
\hline $\begin{array}{c}09173-6841 \\
(1 \mathrm{e})\end{array}$ & $\begin{array}{l}\text { FIN } 363 \text { AB } \\
45571\end{array}$ & $\begin{array}{l}3.4400 \\
\pm 0.0049\end{array}$ & $\begin{array}{r}0.0894 \\
\pm 0.0014\end{array}$ & $\begin{array}{r}140.2 \\
\pm 2.1\end{array}$ & $\begin{array}{r}158.3 \\
\pm 3.1\end{array}$ & $\begin{array}{r}2009.892 \\
\pm 0.020\end{array}$ & $\begin{array}{r}0.4505 \\
\pm 0.0125\end{array}$ & $\begin{array}{r}118.2 \\
\pm 3.5\end{array}$ & 2 & Sod1999 \\
\hline $\begin{array}{c}11009-4030 \\
\text { (1f) }\end{array}$ & $\begin{array}{l}\text { FIN } 365 \\
53840\end{array}$ & $\begin{array}{l}27.09 \\
\pm 0.37\end{array}$ & $\begin{array}{r}0.1523 \\
\pm 0.0047\end{array}$ & $\begin{array}{r}105.1 \\
\pm 1.0\end{array}$ & $\begin{array}{r}102.6 \\
\pm 1.5\end{array}$ & $\begin{array}{r}1993.15 \\
\pm 0.31\end{array}$ & $\begin{array}{r}0.188 \\
\pm 0.044\end{array}$ & $\begin{array}{r}96.4 \\
\pm 6.0\end{array}$ & 4 & Hrt2012a \\
\hline $\begin{array}{c}11190+1416 \\
(2 \mathrm{a})\end{array}$ & $\begin{array}{l}\text { STF } 1527 \\
55254\end{array}$ & $\begin{array}{l}415.0 \\
\pm 15.9\end{array}$ & $\begin{array}{r}2.225 \\
\pm 0.045\end{array}$ & $\begin{array}{r}55.6 \\
\pm 0.5\end{array}$ & $\begin{array}{r}188.0 \\
\pm 0.5\end{array}$ & $\begin{array}{r}2010.503 \\
\pm 0.042\end{array}$ & $\begin{array}{r}0.8511 \\
\pm 0.0033\end{array}$ & $\begin{array}{r}0.50 \\
\pm 0.59\end{array}$ & 3 & Pru2009 \\
\hline $\begin{array}{c}11210-5429 \\
(2 \mathrm{~b})\end{array}$ & $\begin{array}{l}\text { I } 879 \\
55425\end{array}$ & $\begin{array}{l}39.00 \\
\pm 0.19\end{array}$ & $\begin{array}{r}0.2263 \\
\pm 0.0011\end{array}$ & $\begin{array}{r}19.4 \\
\pm 4.9\end{array}$ & $\begin{array}{l}327.8 \\
\pm 3.9\end{array}$ & $\begin{array}{r}2010.410 \\
\pm 0.037\end{array}$ & $\begin{array}{r}0.8530 \\
\pm 0.0040\end{array}$ & $\begin{array}{l}340.3 \\
\pm 4.0\end{array}$ & 2 & Msn1999a \\
\hline $\begin{array}{c}12357-1650 \\
(2 \mathrm{c})\end{array}$ & $\begin{array}{l}\text { FIN } 368 \text { Aa, Ab } \\
61463\end{array}$ & $\begin{array}{l}20.07 \\
\pm 0.10\end{array}$ & $\begin{array}{r}0.1416 \\
\pm 0.0009\end{array}$ & $\begin{array}{r}100.5 \\
\pm 0.8\end{array}$ & $\begin{array}{r}116.4 \\
\pm 0.6\end{array}$ & $\begin{array}{r}1985.52 \\
\pm 0.09\end{array}$ & $\begin{array}{r}0.33 \\
*\end{array}$ & $\begin{array}{r}260.0 \\
*\end{array}$ & 4 & First orbit \\
\hline $\begin{array}{c}13106-3128 \\
(2 \mathrm{~d})\end{array}$ & $\begin{array}{l}\text { RST } 1706 \\
64292\end{array}$ & $\begin{array}{l}91.0 \\
*\end{array}$ & $\begin{array}{r}0.463 \\
\pm 0.014\end{array}$ & $\begin{array}{r}111.9 \\
\pm 1.0\end{array}$ & $\begin{array}{r}63.4 \\
\pm 1.7\end{array}$ & $\begin{array}{r}1999.66 \\
\pm 0.39\end{array}$ & $\begin{array}{r}0.532 \\
\pm 0.0035\end{array}$ & $\begin{array}{l}168.6 \\
\pm 2.6\end{array}$ & 4 & First orbit \\
\hline $\begin{array}{c}13129-5949 \\
(2 \mathrm{e})\end{array}$ & $\begin{array}{l}\mathrm{HDS} 1850 \mathrm{Aa}, \mathrm{Ab} \\
64478\end{array}$ & $\begin{array}{l}31.60 \\
\pm 0.80\end{array}$ & $\begin{array}{r}0.3136 \\
\pm 0.0070\end{array}$ & $\begin{array}{r}90.0 \\
*\end{array}$ & $\begin{array}{r}278.8 \\
\pm 0.2\end{array}$ & $\begin{array}{r}2005.26 \\
\pm 0.11\end{array}$ & $\begin{array}{r}0.340 \\
\pm 0.016\end{array}$ & $\begin{array}{r}50.0 \\
*\end{array}$ & 5 & First orbit \\
\hline $\begin{array}{c}13169-3436 \\
(2 \mathrm{f})\end{array}$ & $\begin{array}{l}\text { I } 1567 \\
64804\end{array}$ & $\begin{array}{l}41.07 \\
\pm 0.19\end{array}$ & $\begin{array}{r}0.3292 \\
\pm 0.0017\end{array}$ & $\begin{array}{r}120.2 \\
\pm 0.66\end{array}$ & $\begin{array}{l}145.8 \\
\pm 0.5\end{array}$ & $\begin{array}{r}2006.456 \\
\pm 0.042\end{array}$ & $\begin{array}{r}0.4582 \\
\pm 0.0042\end{array}$ & $\begin{array}{l}275.4 \\
\pm 0.8\end{array}$ & 2 & Hei1986a \\
\hline $\begin{array}{c}13513-2433 \\
(3)\end{array}$ & $\begin{array}{l}\text { WSI } 77 \\
67620\end{array}$ & $\begin{array}{l}10.485 \\
\pm 0.06\end{array}$ & $\begin{array}{r}0.2827 \\
\pm 0.0014\end{array}$ & $\begin{array}{r}96.4 \\
\pm 0.2\end{array}$ & $\begin{array}{r}351.3 \\
\pm 0.3\end{array}$ & $\begin{array}{r}2009.218 \\
\pm 0.028\end{array}$ & $\begin{array}{r}0.3462 \\
\pm 0.0080\end{array}$ & $\begin{array}{l}137.5 \\
\pm 1.4\end{array}$ & 2 & First, combined \\
\hline $\begin{array}{c}15088-4517 \\
(4 \mathrm{a})\end{array}$ & $\begin{array}{l}\text { SEE } 219 \text { AB } \\
74117\end{array}$ & $\begin{array}{l}70.8 \\
\pm 0.8\end{array}$ & $\begin{array}{r}0.2597 \\
\pm 0.0021\end{array}$ & $\begin{array}{r}71.59 \\
\pm 0.41\end{array}$ & $\begin{array}{r}26.64 \\
\pm 0.61\end{array}$ & $\begin{array}{r}1997.907 \\
\pm 0.105\end{array}$ & $\begin{array}{r}0.6283 \\
\pm 0.0090\end{array}$ & $\begin{array}{r}299.9 \\
\pm 1.1\end{array}$ & 2 & Doc2007d \\
\hline $\begin{array}{c}15339-1700 \\
(4 \mathrm{~b})\end{array}$ & $\begin{array}{l}\text { HDS } 2185 \\
138648\end{array}$ & $\begin{array}{l}60.0 \\
*\end{array}$ & $\begin{array}{r}0.5391 \\
\pm 0.0018\end{array}$ & $\begin{array}{r}40.0 \\
*\end{array}$ & $\begin{array}{r}324.0 \\
\pm 1.0\end{array}$ & $\begin{array}{r}2011.53 \\
\pm 0.02\end{array}$ & $\begin{array}{r}0.3681 \\
\pm 0.0030\end{array}$ & $\begin{array}{r}152.3 \\
\pm 1.0\end{array}$ & 5 & First orbit \\
\hline
\end{tabular}


TABLE 4

Parameters of Orbital Pairs

\begin{tabular}{|c|c|c|c|c|c|c|c|c|c|c|}
\hline WDS & HIP & $\begin{array}{c}\pi_{\text {HIP }} \\
(\text { mas })\end{array}$ & $\begin{array}{l}\text { Sp. } \\
\text { type }\end{array}$ & $\begin{array}{c}V \\
(\mathrm{mag})\end{array}$ & $\begin{array}{l}\Delta \mathrm{Hp} \\
(\mathrm{mag})\end{array}$ & $\begin{array}{c}\Delta y \\
(\mathrm{mag})\end{array}$ & $\begin{array}{l}P \\
(\mathrm{yr})\end{array}$ & $\begin{array}{c}M_{1} \\
\left(M_{\odot}\right)\end{array}$ & $\begin{array}{c}M_{2} \\
\left(M_{\odot}\right)\end{array}$ & $\begin{array}{l}\pi_{\mathrm{dyn}} \\
(\mathrm{mas})\end{array}$ \\
\hline $06359-3605$ & 31547 & $25.39 \pm 0.43$ & G1V & 7.23 & 0.83 & 0.8 & 14.0 & 1.08 & 0.80 & 25.5 \\
\hline $08270-5242$ & 41426 & $18.50 \pm 0.44$ & F5V & 6.50 & 0.87 & 1.0 & 14.8 & 1.61 & 1.28 & 17.5 \\
\hline $08345-3236$ & 42075 & $14.86 \pm 0.57$ & G5IV & 6.43 & $0.38:$ & 0.5 & 17.35 & 1.71 & 1.54 & 14.6 \\
\hline $09173-6841$ & 45571 & $30.64 \pm 0.70$ & F5V & 5.40 & 1.37: & 0.8 & 3.44 & 1.63 & 1.37 & 27.2 \\
\hline $11210-5429$ & 55425 & $9.12 \pm 0.34$ & B9V & 3.90 & 1.49 & 1.5 & 39.0 & 6.43 & 3.68 & 9.1 \\
\hline $12357-1650$ & 61463 & $13.56 \pm 0.76$ & F3IV & 6.70 & 3.10: & 1.7 & 20.1 & 1.79 & 1.23 & 13.3 \\
\hline $13106-3128$ & 64292 & $19.27 \pm 1.23$ & $\mathrm{~K} 0 \mathrm{~V}$ & 9.10 & 1.93 & 1.9 & 91.0 & 0.90 & 0.71 & 19.6 \\
\hline $13129-5949$ & 64478 & $23.72 \pm 0.60$ & G0V & 6.20 & 3.32 & 3.6 & 31.6 & 1.56 & 0.79 & 23.6 \\
\hline $13169-3436$ & 64804 & $23.18 \pm 1.10$ & G5V & 8.06 & 1.00 & 1.1 & 41.1 & 0.96 & 0.84 & 22.7 \\
\hline $13513-2433$ & 67620 & $51.35 \pm 0.45$ & G5V & 6.45 & $\ldots$ & 3.5 & 10.5 & 0.99 & 0.63 & 50.3 \\
\hline
\end{tabular}

TABLE 5

Astrometric Binaries

\begin{tabular}{cclcccl}
\hline \hline WDS & HIP & $\begin{array}{c}\text { Discoverer } \\
\text { code }\end{array}$ & $\begin{array}{c}\rho \\
\left.{ }^{\prime \prime}\right)\end{array}$ & $\begin{array}{c}\Delta V \\
(\mathrm{mag})\end{array}$ & $\begin{array}{c}P \\
(\mathrm{yr})\end{array}$ & \multicolumn{1}{c}{ Comment } \\
\hline $07456-3410$ & 37853 & TOK 193 & 0.310 & 4.0 & $10 ?$ & $\dot{\mu}, \Delta \mu, \mathrm{SB}$ \\
$07490-2455$ & 38146 & TOK 194 & 0.051 & 1.7 & 2.4 & Orbit (Goldin \& Makarov 2007) \\
$07522-4035$ & 38414 & TOK 195 & 0.044 & 1.0 & 7.0 & Orbit (Jancart et al. 2005), SB1 \\
$09191-4128$ & 45705 & CHR 239 & 0.105 & 2.4 & $10 ?$ & $\dot{\mu}, \Delta \mu$ \\
$09275-5806$ & 46388 & CHR 240 & 0.039 & 0.3 & $4 ?$ & $\dot{\mu}$ in HIP2 \\
$09276-3500$ & 46396 & B 2215 & 0.034 & 1.5 & 1.97 & Orbit (ESA 1997) \\
$09416-3830$ & 47543 & $\ldots$ & $\ldots$ & $\ldots$ & $?$ & $\dot{\mu}$ in HIP2 \\
$11056-1105$ & 54214 & new & 0.592 & 5.4 & 30 & Orbit (Gontcharov et al. 2000) \\
$11234-1847$ & 55598 & $\ldots$ & $\ldots$ & $\ldots$ & $?$ & $\dot{\mu}, \Delta \mu$, SB \\
$11318-2047$ & 56245 & new & 1.058 & 4.9 & $200 ?$ & $\Delta \mu$ \\
$13069-3407$ & 64006 & new? & $0.025 ?$ & $?$ & $1 ?$ & Elongation? $\dot{\mu}, \Delta \mu$ \\
$13518-2423$ & 67620 & WSI 77 & 0.283 & 0.5 & 10.5 & $\Delta \mu$, orbit here, SB1 \\
$16534-2025$ & 82621 & WSI 86 & 0.185 & 2.9 & $10 ?$ & $\dot{\mu}, \Delta \mu$ \\
$16571-1749$ & 82956 & $\ldots$ & $\ldots$ & $\ldots$ & $?$ & $\dot{\mu}, \Delta \mu$, SB \\
$17213-5107$ & 84924 & $\ldots$ & $\ldots$ & $\ldots$ & 3.94 & Orbit (ESA 1997), SB \\
\hline
\end{tabular}

TABle 6

Spurious or Enigmatic Binaries

\begin{tabular}{cccccll}
\hline \hline WDS & HIP & $\begin{array}{c}\pi_{\text {HIP }} \\
(\mathrm{mas})\end{array}$ & $\begin{array}{c}\text { Sp. } \\
\text { type }\end{array}$ & $\begin{array}{c}V \\
(\mathrm{mag})\end{array}$ & $\begin{array}{c}\text { Discoverer } \\
\text { code }\end{array}$ & Comment \\
\hline $05074+1839$ & 23835 & $64.8 \pm 0.3$ & G4V & 5.01 & A 3010 & 104 Tau, ADS 3701 \\
$07374-3458$ & 37096 & $9.1 \pm 0.4$ & B8IV & 4.52 & FIN 324 AB & AC orbit in HTM12 \\
$09125-4337$ & 45189 & $4.7 \pm 0.5$ & B8V & 5.56 & FIN 317 Aa,Ab AB is HJ 4188 at 2.'9 & AB 920 at $0^{\prime \prime} 63$ \\
$15462-2804$ & 77235 & $14.1 \pm 1.1$ & F2IV & 6.51 & CHR 50 Aa, Ab & AB is BU 620 \\
$15467-4314$ & 77282 & $21.4 \pm 1.0$ & G5V & 8.08 & I 1276 & Spurious? \\
\hline
\end{tabular}

